\title{
Restoring, releasing or replacing adaptive immunity in chronic hepatitis B
}

\author{
Mala K. Maini ${ }^{1 *}$ and Alice R. Burton ${ }^{1}$
}

${ }^{1}$ Division of Infection and Immunity, Institute of Immunity and Transplantation, University College London, London, UK.

*E-mail:m.maini@ucl.ac.uk

\begin{abstract}
Multiple new therapeutic approaches are currently being developed to achieve sustained, off-treatment suppression of HBV, a persistent hepatotropic infection that kills $\sim 2,000$ people a day. A fundamental therapeutic goal is the restoration of robust HBVspecific adaptive immune responses that are able to maintain prolonged immunosurveillance of residual infection. Here, we provide insight into key components of successful T cell and B cell responses to HBV, discussing the importance of different specificities and effector functions, local intrahepatic immunity and pathogenic potential. We focus on the parallels and interactions between $T$ cell and $B$ cell responses, highlighting emerging areas for future investigation. We review the potential for different immunotherapies in development to restore or release endogenous adaptive immunity by direct or indirect approaches, including limitations and risks. Finally, we consider an alternative HBV treatment strategy of replacing failed endogenous immunity with infusions of highly targeted T cells or antibodies.
\end{abstract}

\section{[H1] Introduction}

HBV is a non-cytopathic, partially double-stranded DNA virus that exclusively infects hepatocytes. Although $>95 \%$ of cases of adult-acquired HBV result in an acute-resolving infection ${ }^{1}$, acquisition at birth or in early childhood commonly results in chronic infection. When persistent infection is established, the immune response fails to control the virus and can instead trigger tissue damage leading to liver cirrhosis and cancer. An estimated 260 million people worldwide are chronically infected with $\mathrm{HBV}$, resulting in $>700,000$ deaths a year from cirrhosis and hepatocellular carcinoma $(\mathrm{HCC})^{2}$. There are now intensive efforts to develop strategies for global eradication of HBV, with the WHO having set a target to eliminate the virus by $2030^{2-4}$. However, without further scale-up of prevention and treatment, new HBV infections are predicted to remain close to 3 million a year in $2030^{2}$. Proposed approaches to tackle this urgent issue can be considered in three categories. First, better implementation of the preventative vaccine and other public health measures to limit ongoing transmission are vital steps towards the long-term goal of global 
eradication $2,3,5$. As viral persistence mainly occurs when HBV is acquired through mother to child transmission, inclusion of HBV in neonatal vaccination programmes is key. Second, $<10 \%$ of existing cases of chronic HBV infection ( $\mathrm{CHB}$ ) are currently diagnosed and only $8 \%$ of these receive treatment ${ }^{2,3,5}$; this huge shortfall needs to be addressed to enable more widespread access to antiviral agents that can suppress viraemia and reduce complications. Third, the path to global eradication and individualised cure would be greatly facilitated by the development of novel therapeutic approaches that are able to achieve sustained offtreatment responses in the majority of cases $^{6}$.

Persistent HBV replication in the setting of current treatment with reverse transcriptase inhibitors is propagated by episomal, covalently closed circular (ccc) DNA that persists within the nuclei of infected hepatocytes ${ }^{6}$. Among the new generation of antiviral agents under development, some aim to directly or indirectly target $\operatorname{cccDNA}{ }^{7}$, but they are unlikely to eradicate all cccDNA traces within the large burden of infected hepatocytes ${ }^{6,8,9}$. Yet a single virion has been found to be sufficient to launch HBV infection that can spread to almost $100 \%$ of hepatocytes in chimpanzees ${ }^{10}$. Thus, a strong impetus exists for treatment regimens that mimic the response observed in naturally-resolving HBV infection, harnessing synergistic aspects of the immune response to repress residual virus through tight, longterm immune control ${ }^{11}$. This scenario would represent a long-term functional cure, which is defined as sustained loss of detectable HBV surface antigen (HBsAg) in serum following termination of therapy ${ }^{12}$. The induction of immune responses with the additional capacity to eradicate hepatocytes with integrated HBV DNA might also help to reduce the residual production of HBsAg and the ongoing risk of carcinogenesis in patients receiving nucleoside or nucleotide analogue therapy ${ }^{13,14}$. The translation of novel immunotherapies to the clinic to achieve these goals now has unprecedented opportunities, galvanised by advances in immune targeting in cancer ${ }^{15,16}$.

Optimal viral control is generally dependent upon the co-ordination of both innate and adaptive immune responses. Multiple components of both branches of the immune system are impaired in CHB but, if supplemented, the virus remains susceptible to their antiviral effects $^{17-19}$. Activation of cell intrinsic immunity, or the abundant innate immune cell types within the HBV-infected liver, represent potential strategies for the treatment of $\mathrm{CHB}^{17,19}$. However, innate immune effectors are not typically able to selectively target only infected hepatocytes, potentially creating a difficult trade-off between efficacy and toxicity.

Although more elusive than innate cells, HBV-specific adaptive immune responses offer a more precisely targeted immunotherapeutic strategy. HBV-specific CD8 ${ }^{+} \mathrm{T}$ cells are uniquely able to recognise and direct their antiviral function towards HBV-infected hepatocytes, but these cells are profoundly depleted and dysfunctional in $\mathrm{CHB}^{18,20,21}$. The molecular mechanisms contributing to the exhausted state of antiviral T cells in CHB are covered elsewhere ${ }^{18}$ and summarised in Box 1.

In addition to T cell-mediated immunity, the importance of the humoral immune response against HBV has been clearly demonstrated by multiple cases of viral reactivation (of either 
resolved or chronic infection) triggered by rituximab-mediated $\mathrm{B}$ cell depletion ${ }^{22}$. The first ex vivo analyses have now revealed that, in contrast to $\mathrm{HBV}$-specific $\mathrm{T}$ cells, B cells specific for $\mathrm{HBsAg}$ persist in donors with $\mathrm{CHB}$ at similar frequencies to those with resolved or vaccineinduced immunity ${ }^{23-25}$. However, $\mathrm{HBsAg}$-specific $\mathrm{B}$ cells in $\mathrm{CHB}$ show some analogous features to exhausted HBV-specific T cells, including impaired signalling, differentiation, homing and effector functions ${ }^{23-25}$ (Box 1).

This Review will focus on new insights into features of effective $B$ cell and $T$ cell responses towards HBV, examining the parallel constraints and interactions between these two complementary components of the adaptive immune system and the mechanisms by which they contribute to antiviral immunity. The opportunities to either boost failed endogenous B cell and T cell immunity, or to supplement it with exogenous supplies of powerful immune mediators are also considered.

[H1]-Features of adaptive immunity to HBV

\section{[H2] Antigen specificity of T cells}

T lymphocytes and B lymphocytes have a unique level of specificity imposed by their highly variable antigen receptors, which are generated through a series of somatic recombination events $^{26}$. Their discerning sensitivity to minor variations in antigens gives a high degree of precision to their viral targeting. However, the fastidiousness of adaptive responses increases the complexity of harnessing them therapeutically, as careful consideration needs to be given to the most important viral antigens to be targeted. Their fine specificity also means that single viral mutations can result in selection for viral escape in response to immune pressure. The occurrence of T cell escape mutations is generally assumed to be much rarer in HBV than in HIV or HCV. Most T cell studies carried out in the field to date have focused on responses to HBV epitopes presented by the common class I HLA allele HLA-A*0201, in which isolated cases of escape mutations were described ${ }^{27,28}$, but T cell responses were generally considered too weak to exert selection pressure ${ }^{29,30}$. However, two studies, that took a population-based approach to comprehensively examine the effect of HLA genotype on HBV sequences, identified more mutations suggestive of immune selection pressure by $\mathrm{CD}^{+} \mathrm{T}$ cell responses ${ }^{31,32}$.

The immunodominance and protective hierarchy of different $\mathrm{CD} 8^{+} \mathrm{T}$ cell specificities for HBV has been difficult to assess, given the very low frequency of responses and limited knowledge of HBV epitopes restricted by alleles other than HLA-A*020120. Early data examining only HLA-A2-restricted responses suggested that an epitope from the HBV core antigen ( $\mathrm{HBCAg}$ ) termed $\mathrm{HBc} 18-27$ was associated with natural resolution of HBV infection ${ }^{33,34}$; however, this association might not apply to HBcAg epitopes restricted by other alleles. One study in 2018 has underscored a protective role for $\mathrm{CD} 8^{+} \mathrm{T}$ cell responses against epitopes from HBCAg and HBV polymerase independently of their HLA restriction, associating them with prevention of viral rebound following treatment interruption ${ }^{35}$. 
$\mathrm{CD}^{+} \mathrm{T}$ cells in $\mathrm{CHB}$ typically circulate at extremely low frequencies regardless of specificity, often below ex vivo detection using HLA-peptide multimers, intracellular cytokine staining or enzyme-linked immune absorbent spot (ELISPOT) quantification 20,36,37. Two studies surmounted this limitation, enriching for HLA-A2 binding or HBV-multimer binding $\mathrm{CD} 8^{+} \mathrm{T}$ cells to enable in-depth comparison of HBV-specific T cells according to specificity ${ }^{38,39}$. This approach revealed that $\mathrm{HBsAg-specific} \mathrm{responses} \mathrm{were} \mathrm{only} \mathrm{detectable} \mathrm{in} \mathrm{a} \mathrm{minority} \mathrm{of}$ donors with low-level CHB (HBV e antigen (HBeAg)-negative infection), whereas responses directed against HBV polymerase or HBcAg had distinct 'fingerprints' that included functional differences ${ }^{38,39}$.

Another factor that could dictate the utility of T cells of different specificities is the distribution and presentation of HBV antigens within the liver. Staining of HBV-infected human liver sections with antibodies specific for an HBcAg or HBsAg epitope bound to HLAA*0201 showed topologically distinct distributions of these different specificities, which was supported by differences in the efficiency of presentation of these two HBV epitopes in primary human hepatocytes and hepatoma cell lines ${ }^{40}$. This finding adds a further level of spatio-temporal complexity, potentially hindering T cells of the correct HBV specificity encountering hepatocytes expressing their cognate antigen.

\section{[H2] Antigen specificity of B cells}

Less is known about the specificity of B cell responses to HBV, although different antibodies are routinely used to distinguish clinical phases of infection. B cells in patients infected with HBV are capable of differentiating into plasma cells producing polyclonal antibodies directed against a range of $\mathrm{HBV}$ antigens, including $\mathrm{HBcAg}, \mathrm{HBeAg}$ and the large, middle and small forms of $\mathrm{HBsAg}$ are produced with varying kinetics ${ }^{41}$. HBcAg-specific IgM (anti-HBc) appears early in infection and can co-exist with a high level of HBV replication ${ }^{42}$. As the only confirmatory marker of previous or current infection, detection of anti-HBc has mainly been used for diagnostic purposes and a possible role in pathogenesis has largely been ignored. However, passive immunisation of a single chimpanzee with monoclonal anti-HBc delayed HBV clearance ${ }^{43}$. Data have also suggested that anti-HBc can play a pathogenic role in progression towards acute fulminant hepatitis, forming large antigen-antibody complexes with HBcAg in the liver that can activate the classical complement pathway to drive liver necrosis ${ }^{44,45}$. In addition to anti-HBc IgG, which is detectable throughout chronic infection, anti-HBc IgM antibodies, characteristic of acute infection, can become detectable again in the serum of patients undergoing flares of $\mathrm{CHB}^{46}$. Whether anti- $\mathrm{HBC}$ IgM is generated in response to liver damage or actually contributes to it is not fully understood.

In contrast to anti-HBc, antibodies targeting HBsAg and $\mathrm{HBeAg}$ (anti-HBs and anti-HBe) appear later in acute infection and are associated with favourable outcomes of infection ${ }^{47}$. Following successful control of the virus and disease resolution, HBsAg is lost from the blood and HBsAg-specific antibodies become detectable. A role for neutralising anti-HBs 
antibodies in preventing de novo HBV infection is supported by their protective effects (following transfer of polyclonal hepatitis B immunoglobulins from HBV-immune individuals) in the settings of liver transplantation, post-exposure prophylaxis of neonates born to HBsAg-positive mothers ${ }^{48,49}$ and in response to prophylactic vaccination.

Production of anti-HBe antibodies is only detected in a portion of patients with chronic infection, and is delayed compared to anti-HBc. Detection of anti-HBe commonly coincides with an initial reduction in HBV DNA; however, no function of this antibody in immune control has been shown ${ }^{47}$. In stark contrast to acute-resolving HBV infection, most patients with CHB fail to produce detectable levels of anti-HBs antibodies. It has been unclear whether this is due to sequestration of antibody by the large amounts of soluble HBsAg produced, a lack of HBsAg-specific B cells or their functional exhaustion. However, work characterising HBsAg-specific B cells in patients with persisting $\mathrm{HBsAg}$ levels revealed preservation of antigen-specific $B$ cell frequencies, but impaired production of anti-HBs, in contrast to efficient antibody production by HBsAg-specific B cells from HBV-vaccinated controls ${ }^{23,25,50,51}$. HBsAg-specific B cells in patients with CHB were enriched for B cells with an atypical memory phenotype, to the detriment of conventional, classical memory $B$ cells ${ }^{23,25}$. Future work will address whether $B$ cells specific for $\mathrm{HBcAg}$ retain a classical memory phenotype in line with the ongoing production of anti-HBc antibodies in $\mathrm{CHB}$.

\section{[H2] Antiviral and pathogenic mediators}

$\mathrm{CD}^{+} \mathrm{T}$ cells can control HBV infection through cytolytic and non-cytolytic effector functions (Figure 1$)^{52-54}$. Through the production of cytolytic molecules including perforin and granzyme B by T cells, some degree of target cell death (Figure 1a) is probably required for the elimination of infected hepatocytes and could thereby also remove integrated HBV-DNA to reduce HCC risk. However, non-cytolytic control of HBV, through the release of antiviral cytokines such as IFN $\gamma$ and TNF, has the potential to act on multiple hepatocytes while avoiding extensive liver damage. The capacity of T cells to exert anti-HBV effects through IFN $\gamma$ and TNF (Figure 1b) was first shown in a transgenic HBV mouse model ${ }^{55}$, and was subsequently also proven to be operative against HBV-replicating human hepatocytes ${ }^{56-58}$. These cytokines have the capacity to degrade cccDNA by activating hepatocyte ABOBEC3 deaminases ${ }^{58,59}$. T cells can also be manipulated to activate the ABOBEC3 antiviral pathway in HBV-infected hepatocytes through the expression of lymphotoxin- $\beta$-receptor ligands (Figure $1 b$ ), a finding that is being exploited in adoptive cell therapy trials described later ${ }^{60}$.

The best-recognised antiviral effector function of B cells is their development into plasma cells that produce neutralising antibodies, preventing entry of the virus to target cells either through steric obstruction or through direct binding to the receptor-binding site on virions 61,62. During HBV infection, only antibodies directed against the envelope protein (antiHBs) have neutralising activity, underscored by their ability to recognise and bind to key viral epitopes required for infectivity ${ }^{63,64}$. With precise mapping of the HBV entry receptor NTCP, 
it has been possible to identify epitopes within the pre-S1 domain of $\mathrm{HBsAg}^{65,66}$. Antibodies against the pre-S1 domain prevent de novo infection by binding HBsAg on the surface of infectious virions and obstructing interactions with NTCP ${ }^{66,67}$ (Figure 2a). In preventing binding to NTCP, anti-HBs can also have a role in limiting HBV spread within the already chronically infected liver through actions comparable to that noted for the peptide inhibitor myrcludex $B^{67-69}$. Similarly, antibodies that target the immunodominant a-determinant region of the antigenic loop of HBsAg (common to all HBV strains) block binding to heparan sulphate glycoproteins (HSPGs) expressed on the hepatocyte surface, thereby preventing initial virus attachment ${ }^{70}$. However, during chronic HBV infection, any antibodies produced might be depleted by the large amounts of circulating subviral particles (Figure $2 b$ ) that sequester anti-HBs in immune complexes ${ }^{71,72}$.

Through engagement of classic crystallisable fragment receptors (FcRs) and non-classic Ctype lectin receptors on effector cells, antibodies can also exert a number of Fc-dependent effector functions to eliminate virus-infected cells. These functions include antibodydependent cellular phagocytosis (ADCP) and antibody-dependent cell-mediated cytotoxicity $(A D C C){ }^{73,74}$ (Figure 2c). ADCC-mediated depletion requires $\mathrm{HBs} A g$ to be expressed on the membrane (or in the close vicinity) of infected hepatocytes for antibody binding and killing by neighbouring Fc-bearing effectors. This process could occur during hepatocyte secretion of virions and subviral particles of HBsAg and is supported by some immunohistological staining of HBV-infected liver biopsy samples that demonstrated both cytoplasmic and membranous HBsAg staining ${ }^{75,76}$. Furthermore, through engaging the neonatal Fc-receptor on infected hepatocytes, anti-HBs IgG might also interact with cytoplasmic HBsAg and inhibit $\mathrm{HBsAg}$ secretion from within infected cells ${ }^{77,78}$. An additional potential mechanism of action of antibodies is a 'vaccinal effect', whereby antigen-antibody immune complexes can bind FcRs on dendritic cells to promote T cell priming ${ }^{79}$ (Figure $2 \mathrm{c}$ ). This mechanism has been exploited in the development of an anti-HBs-HBsAg immune complex-based therapeutic vaccination strategy for $\mathrm{CHB}^{80}$.

In addition to developing into antibody secreting cells, B cells can guide the development of lymphoid tissues, shape $T$ cell responses and regulate immunity through the secretion of cytokines $^{81}$. During viral infections and following engagement of the $B$ cell receptor (BCR) and CD40, B cells are able to produce IFN $\gamma$, TNF and IL-6 $23,81,82$, which can all have potent non-cytolytic antiviral activity during HBV infection ${ }^{55,58,83-85}$ (Figure $2 \mathrm{~d}$ ). In vitro, exogenous application of IL- 6 downregulates expression of NTCP by HBV-infected hepatocytes ${ }^{83}$, and can disrupt viral transcription and cccDNA acetylation ${ }^{84,85}$. Through the production of IL- 6 and the promotion of $T$ follicular helper $\left(T_{F H}\right)$ cell responses, $B$ cells can also drive the initiation of antiviral immune responses ${ }^{86}$ and assist in viral control during latter stages of infection ${ }^{87}$. 


\section{[H2] Crosstalk between T cells and B cells}

Central to the activation and regulation of $B$ cell functionality are the interactions between $\mathrm{CD}^{+} \mathrm{T}_{\mathrm{FH}}$ cells and $\mathrm{B}$ cells occurring within the germinal centre ${ }^{88}$ (Figure 3 ). $\mathrm{T}_{\mathrm{FH}}$ cells are a

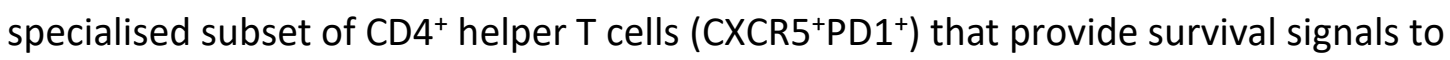
germinal centre $B$ cells, thereby facilitating the selection and differentiation of $B$ cells with high specificity for antigens. The interaction between $\mathrm{CD}^{+} \mathrm{T}_{\mathrm{FH}}$ cells and $\mathrm{B}$ cells is particularly relevant for T-cell dependent $B$ cell responses such as the generation of anti-HBs, whereas antibody responses to $\mathrm{HBCAg}$ can be generated via both T-cell dependent and T-cell independent pathways ${ }^{20,89}$. Production of anti-HBs antibodies might therefore be hindered by the low frequency of functional HBV-specific CD4 ${ }^{+} \mathrm{T}$ cells at different stages of HBV infection $30,36,90,91$. A subset of $T_{F H}$ cells (referred to as $T$ follicular regulatory ( $T_{F R}$ ) cells) have also been shown to express the regulatory transcription factor FOXP3 and can repress other $T_{F H}$ cells, thereby limiting the number of $T_{F H}$ cells within the germinal centre and inhibiting the selection of non-antigen specific $B$ cells ${ }^{92}$. An analogous population might be responsible for impairing anti-HBs B cell responses in HBV. This concept was first eluded to in a study in 1983, which demonstrated that co-culture of $B$ cells and T cells from vaccinated healthy controls with T cells from HBsAg carriers suppressed anti-HBs production ${ }^{93}$, implicating a role for regulatory $\mathrm{T}$ cells in impairing $\mathrm{T}_{\mathrm{FH}}$ cells and anti-HBs production in $\mathrm{CHB}$. These data are consistent with reports of $T$ regulatory $\left(T_{\text {reg }}\right)$ cell and $T_{F R}$ cell mediated suppression of $\mathrm{HBsAg}$-specific $\mathrm{T}_{\mathrm{FH}}$ cells in HBV-infected mice and patients, which correlate with impaired induction of anti-HBs responses ${ }^{94-96}$.

Interactions between $\mathrm{CD}^{+} \mathrm{T}$ cells and B cells are also reliant on the intrinsic ability of B cells to present antigens via major histocompatibility complex ( $\mathrm{MHC}$ ) class II. The antigenpresenting capacity of $\mathrm{B}$ cells has received little consideration in the context of HBV infection, yet it might play a part in differences in antibody production in response to different components of $\mathrm{HBV}^{97}$. The immunogenicity of $\mathrm{HBCAg}$ is postulated to derive, in part, from its capacity to self-assemble into highly immunogenic virus-like particles that can efficiently crosslink BCRs to activate naive $B$ cells in a superantigen-like manner ${ }^{98}$. In mice, uptake of $\mathrm{HBCAg}$ by the BCR, rather than by professional antigen-presenting cells, was required for efficient priming of naive $T$ cells and antibody production following immunisation with $\mathrm{HBCAg}^{97}$.

Although the co-operation of $\mathrm{CD}^{+} \mathrm{T}$ cells and $\mathrm{B}$ cells is clearly important for the generation of high-affinity antibody and $T$ cell responses, interactions between $\mathrm{B}$ cells and $\mathrm{CD} 8^{+} \mathrm{T}$ cells might also have important implications for adaptive immunity in HBV infection. Through binding and internalisation of antigens via BCR-mediated endocytosis, B cells are also able to cross-present antigens on $\mathrm{MHC}$ class I to $\mathrm{CD} 8^{+} \mathrm{T}$ cells, a process suggested to be essential for priming of HBcAg-specific $\mathrm{CD} 8^{+} \mathrm{T}_{\text {cells }}{ }^{99}$. However, cross-presentation of antigens to $\mathrm{CD} 8^{+} \mathrm{T}$ cells can also have deleterious effects for antiviral B cells; for instance, when B cell presentation of HBsAg epitopes on MHC class I primes cytotoxic T cells that kill HBsAgspecific $B$ cells ${ }^{100}$. B cells can also have more globally suppressive effects on $T$ cell function; 
work from our group previously identified an expansion of IL-10-producing regulatory B cells in patients with CHB undergoing spontaneous disease flares, that suppressed HBV-specific $\mathrm{CD}^{+} \mathrm{T}$ cell function in an IL-10-dependent manner ${ }^{101}$.

\section{[H2] Intrahepatic responses}

Most studies in patients with $\mathrm{CHB}$ have relied on assessment of immune responses in the periphery, despite the fact that this hepatotropic virus only replicates and causes disease in the liver. An accumulating body of literature underscores the importance of studying immunity at the site of disease, where tissue-resident lymphocytes can be highly adapted to optimal functioning in the local microenvironment. Tissue-resident memory $T\left(T_{R M}\right)$ cells have been shown to be critical for frontline immune-surveillance of pathogens in mice, owing to their capacity to persist in the relevant site without recirculating, ready to mount immediate effector function ${ }^{102-104}$.

We have shown that a subset of $\mathrm{CD}^{+} \mathrm{T}$ cells in human liver have prototypical phenotypic and functional features of $\mathrm{T}_{\mathrm{RM}}$ cells, maintaining potent non-cytolytic antiviral functionality and expanding preferentially in donors with efficient $\mathrm{HBV}$ control ${ }^{105}$. The majority of intrahepatic HBV-specific $\mathrm{CD}^{+} \mathrm{T}$ cells express markers required for tissue retention (for example, CD69 with or without CD103) ${ }^{105}$, consistent with their known enrichment within the liver ${ }^{106}$. These liver-resident responses could be targeted in future immunotherapeutic approaches, either by attempting to expand the small fraction of HBV-specific CD8 ${ }^{+} \mathrm{T}$ cells persisting in the HBV-infected liver, or by inducing new responses that reside in the liver and that recapitulate the antiviral and survival advantages of $T_{R M}$ cells.

We observed that HBsAg-specific B cells can also home to the human HBV-infected liver ${ }^{23}$. Whether these B cells or other B cell subsets can acquire long-lived liver residence, and how they might contribute to viral control and/or disease remains to be established. Production of mediators such as antibodies and antiviral cytokines by $B$ cells stationed at the site of infection is probably advantageous for HBV control. On the other hand, B cells in the liver might avoid the requisite productive interactions with $T_{F H}$ cells discussed earlier and instead be subjected to the tolerogenic influences of the hepatic environment. This concept is supported by our finding of atypical memory B cells with high expression of the archetypal hepatic immune checkpoint protein PD-1 accumulating in the HBV-infected liver ${ }^{23}$.

Little research has been done to understand how $T$ cells and $B$ cells might be interacting in the liver. It has long been recognised that ectopic lymphoid structures resembling germinal centres can arise in non-lymphoid tissues and assist in the activation, proliferation and differentiation of B cell responses, overturning the dogma that antigen-specific responses are solely initiated in lymphoid tissue ${ }^{107,108}$. In fact, such non-lymphoid organ germinal centre reactions can be better at generating cross-reactive neutralising antibodies to prevent viral escape than those in classic lymphoid tissues ${ }^{109}$. Although some attempts to identify intrahepatic lymphoid follicles in the HBV-infected liver have been made ${ }^{108,110}$, how 
these aggregations might contribute to immune control has been largely unexplored. However, one study testing the immunotherapeutic effects of TLR7 agonists in HBV-infected chimpanzees demonstrated transient induction of $B$ cell and $T$ cell aggregates in portal regions, coinciding with prolonged suppression of serum viral DNA and antigens ${ }^{111}$.

The sequestration of subsets of specialised hepatic T cells and B cells that cannot be sampled in the blood emphasises the need for immune monitoring of novel therapies to include the liver compartment. Liver biopsies are the gold standard for assessing HBV disease activity, enabling analysis of immune interactions using surplus tissue not required for histological diagnosis, but they are being rapidly replaced by noninvasive methods such as fibroscan or serum markers like the enhanced liver fibrosis test (ELF) ${ }^{112}$. However, we have shown that fine needle aspirates, which are better tolerated than biopsies and therefore suitable for longitudinal monitoring, sufficiently sample all intrahepatic immune populations including liver-resident lymphocytes ${ }^{113}$.

\section{[H2] Pathogenic role}

Many B cell and T cell mediators of antiviral efficacy also have pathogenic potential and could inadvertently drive liver damage. Antibodies can have predominantly virus neutralising effects, but they might also engage accessory cells to lyse infected hepatocytes by ADCC, which would induce liver injury. Evidence from animal models and human studies suggest that functional $\mathrm{CD} 8^{+} \mathrm{T}$ cell responses can control HBV without substantial liver damage ${ }^{18,20,114,115}$. Cytokines such as IFN $\gamma$, produced by HBV-specific T cells and bystander T cells, exert predominantly non-cytolytic antiviral effects but do also have the capacity to contribute to necroinflammatory liver damage ${ }^{115}$. Any immunotherapeutic approach to HBV cure will, therefore, require careful titration and might necessitate some degree of 'hepatic flare' to achieve adequate HBV elimination.

Immunotherapeutic targets are often homeostatic constraints that have a vital physiological role in preventing exaggerated immune responses and maintaining tolerance. Thus, a degree of tissue injury or autoimmunity are risks that have to be considered with all immunotherapies and modifications to enhance precision and minimise off-target effects are needed. The risk of hepatic flares with novel immunotherapeutic approaches will necessitate careful patient selection, as discussed elsewhere ${ }^{18}$, with initial testing restricted to patients who have low viral loads as a result of disease stage or antiviral treatment. New assays are needed for candidates being considered for immunotherapies that can estimate the number of hepatocytes expressing HBV antigens that might be targeted by boosted immune responses, as well as the likely reserve of heathy hepatocytes with regenerative capacity.

Controlled hepatocyte lysis could have the advantage of promoting cell division and reducing cccDNA (particularly in the presence of an entry inhibitor) by diluting it amongst dividing daughter cells ${ }^{116}$. However, it also holds the theoretical risk of driving clonal 
outgrowth of hepatocytes bearing pro-carcinogenic integrations. Similarly, checkpoint inhibitors, although able to boost protective anti-tumour responses once HCC is established, might also carry a risk of promoting hepatitis and ultimately carcinogenesis if their prolonged use drives a suboptimal necroinflammatory response with antigen persistence ${ }^{117}$.

\section{[H1] Restoration of adaptive immunity}

\section{[H2] Direct approaches}

Having described some of the key features of adaptive immunity to HBV, we will now consider direct and indirect strategies to boost endogenous immunity (Box 2, Figure 4).

\section{[H3] Therapeutic vaccination}

Previous efforts to restore endogenous immunity to HBV have centred on therapeutic vaccination, primarily focused on $\mathrm{HBsAg}^{118,119}$. Their lack of success has been attributed to a combination of inadequate immunogenicity to overcome the underlying $T$ cell exhaustion, and suboptimal selection of viral antigens and patients ${ }^{18,119-121}$. The current working model of an idealised therapeutic vaccine approach has been addressed in recent reviews ${ }^{18,119-121}$. To summarise, the goal is to achieve greater immunogenicity than previous generations of vaccines, target all major HBV antigens and select patients with optimal pre-existing immunity. Future vaccines should aim to harness B cells as well as T cells in light of the previously neglected role for humoral immunity in HBV control. Data discussed in the following sections suggest that new approaches being developed to substantially reduce HBV antigens could potently enhance therapeutic vaccine efficacy. Alternatively - or additionally - adjunctive immune restoration might be required to facilitate vaccinedirected boosting. Therapeutic vaccines should provide a useful backbone to the immunotherapeutic approaches discussed later (Figure 4), as they will focus immune boosting towards HBV. By immunogenic priming outside the tolerogenic liver environment, therapeutic vaccines might also be able to generate new antigen-specific $T$ cells and $B$ cells that can then be protected from exhaustion, thereby bypassing the need to recover existing low-frequency responses.

\section{[H3] Checkpoint modulators}

T cell checkpoint inhibitors, such as those targeting PD1, are front-runners for clinical translation as immunotherapeutics to boost responses to HBV therapeutic vaccines. This choice is supported by their success in cancer immunotherapy and proof-of-concept trials that show their capacity to enhance therapeutic vaccination against lymphocytic choriomeningitis virus (LCMV) and woodchuck hepatitis virus ${ }^{122,123}$. Although the PD1 pathway is considered a critical regulator of hepatic tolerance ${ }^{124-126}$, initial results of in vivo PD1 blockade in patients with HCC, or uncomplicated HBV infection (single dose in a small 
trial of 22 patients with $\mathrm{CHB}$ ), have not shown prohibitive liver toxicity ${ }^{127,128}$. Thus, combining PD-1 blockade with an immunogenic vaccine following antigen load reduction remains a compelling strategy.

However, emerging data point to a complex role for PD1 in T cell homeostasis ${ }^{129-132}$, in which the molecule is additionally upregulated upon T cell activation and found strongly expressed on tissue-resident $\mathrm{T}$ cells that maintain rapid functionality upon $\mathrm{T}$ cell receptor (TCR) engagement ${ }^{105,133}$. Although genetic deletion of PD1 enhances short-term capacity of T cells to kill HBV-expressing hepatoma cells in a PDL1 ${ }^{\text {hi }}$ microenvironment ${ }^{134}$, it conversely unleashes excessive $T$ cell proliferation, driving terminal senescence in mouse and human $\mathrm{CD}^{+} \mathrm{T}$ cells ${ }^{134,135}$. These findings are consistent with the concept that immune checkpoints, such as PD1, help to sustain T cells in the setting of continuous antigen stimulation, enabling them to continue to exert some degree of control ${ }^{130,132}$. Genetic knockdown of PD1 on human T cells also induces compensatory upregulation of alternative checkpoints such as CTLA4 and TIM3 ${ }^{134}$ that have also been shown to restrain HBV-specific T cells in vitro ${ }^{136,137}$. The multi-layered and heterogeneous nature of checkpoint inhibition implies that selection of agents might have to be personalised, underscoring the need for biomarkers to predict responsiveness. An alternative solution is the combination of more than one checkpoint inhibitor or the addition of a co-stimulator; both these approaches are already in clinical trials for $\mathrm{HCC}^{138}$ and other cancers, but might prove too toxic to justifiy in patients with uncomplicated CHB who are otherwise healthy .

The finding that PD1 is also expressed on human B cells and enriched on the HBsAg-specific population ${ }^{23,25}$ raises the possibility that humoral immunity might also be amenable to modulation by PD-1 blockade, as previously reported in simian immunodeficiency virusinfected macaques ${ }^{139}$. We noted that PD-1 ${ }^{\text {hi }} B$ cells were transcriptionally wired for antiviral efficacy as they had the highest levels of T-bet ${ }^{23}$, shown to be critical for isotype switching and effective antiviral control in mice ${ }^{140-142}$. In vitro rescue of $B$ cell survival and effector function (antibody and cytokine production) was only possible when PD-1 blockade was combined with CD40-L stimulation, IL-2 and IL-2123,25. Whether these combinations or others could rescue functional humoral antiviral immunity in vivo remains speculative. One concern is that such an approach might favour further expansion of the T-bet ${ }^{\text {hi }}$ atypical memory B cell subset that expresses the highest level of PD-1 (particularly in the liver), which are increasingly implicated in the pathogenesis of autoimmunity ${ }^{143}$. In line with this concern, a small study of combined PD1-CTLA4 blockade in 39 patients with melanoma found an expansion of $\mathrm{CD} 21^{\text {lo }}$ (atypical) B cells in those who went on to develop immunerelated adverse events ${ }^{144}$.

\section{[H3] Immunomodulatory cytokines}

IFN $\alpha$, used extensively in therapeutic control of $\mathrm{HBV}$, exerts direct antiviral effects and boosts natural killer (NK) cell function, but tends to decrease the frequency of virus-specific 
T cells ${ }^{145-147}$. Instead, we observed that the alternative pro-inflammatory cytokine IL-12 is able to boost functional HBV-specific $\mathrm{CD} 8^{+} \mathrm{T}$ cells, particularly in combination with PD1 blockade ${ }^{147}$. IL-12 might reconstitute antiviral functionality through its capacity to downregulate $\mathrm{PD} 1^{147}$ and to enhance the metabolic flexibility of $\mathrm{HBV}$-specific $\mathrm{CD} 8^{+} \mathrm{T}$ cells ${ }^{148}$. HBVspecific $C D 8^{+} T$ cells have defective mitochondria ${ }^{148,149}$, also observed in mouse models of chronic viral infection (LCMV) and tumours (melanoma) ${ }^{150,151}$, that limit their capacity to utilise oxidative phosphorylation. We found that IL-12 can enhance mitochondrial potential and the capacity of HBV-specific $\mathrm{CD}^{+} \mathrm{T}$ cells to optimise their glucose metabolism by engaging oxidative phosphorylation ${ }^{148}$. As systemic IL-12 has been poorly tolerated in cancer trials ${ }^{152}$, it could be targeted directly to the liver or incorporated into a vaccine construct; the latter approach is already in clinical trials of a DNA vaccine for $\mathrm{CHB}^{18}$.

IL-12 would also be expected to activate NK cells, which might be able to contribute to HBV control and/or exacerbate liver damage ${ }^{153,154}$. A potential drawback is the capacity of NK cells to act as a rheostat, limiting antiviral $T$ cell and B cell immunity ${ }^{155,156}$. It has been observed in humans that activated NK cells, expressing the death ligand TRAIL, are enriched within the liver-resident pool of NK cells of the HBV-infected liver, and are able to remove HBV-specific T cells expressing the TRAIL-R2 death receptor or NKG2D ligands ${ }^{157-159}$. Our unpublished data using a mouse model of HBV suggests that NK cells can also constrain the $T$ cell and $B$ cell response to therapeutic vaccination in vivo (M.K.M., unpublished observations). Thus, immunotherapeutic approaches that activate both innate and adaptive antiviral immunity, such as IL-12 and the newly described combination of anti-NKG2A with anti-PD-1 ${ }^{160}$, might need to additionally block pathogenic interactions between antiviral $T$ cells and NK cells for optimal efficacy in HBV.

\section{[H3] Beyond current targets}

There are a range of alternative T cell checkpoints, co-stimulatory pathways and immunomodulatory cytokines that have been tested in mouse models of chronic viral infection and/or patients with cancer, and could potentially be considered for boosting responses to therapeutic vaccination in $\mathrm{HBV}^{18,161,162}$. However studies of these different checkpoint inhibitors, co-stimulators and/or cytokine manipulation have shown highly variable capacity to rescue $T$ cells in vitro within the heterogeneous cohorts of patients with $\mathrm{CHB}^{18,163}$. Detailed dissection of 'clusters' of transcriptional and phenotypic markers of exhaustion can enable rational individualised selection of checkpoints ${ }^{129}$; for example, using T cell differentiation status to predict responsiveness to PD-1 blockade ${ }^{164,165}$.

Another innovative approach is the modulation of T cells at a more fundamental level, by specifically reprogramming their mitochondria or other aspects of cellular metabolism. In addition to IL-12 discussed earlier, mitochondrial antioxidants MitoTEMPO and mitoquinone can scavenge reactive oxygen species to enhance expression of key proteins from the electron transport chain and rescue functional HBV-specific T cell responses from patients 
with $\mathrm{CHB}^{149}$. Future approaches should additionally aim to increase PGC1 $\alpha$ to promote mitochondrial biogenesis, for example by CD137 (also known as 4-1BB) costimulation, which can enhance T cell efficacy in a mouse model of B16 melanoma ${ }^{151,166}$.

An additional relevant metabolic target is the amino acid arginine, which might be depleted in the HBV-infected liver by arginase-1-expressing granulocytic myeloid-derived suppressor cells and hepatocytes ${ }^{167,168}$. T cells require constant supplies of arginine to drive oxidative phosphorylation and promote T cell survival, as they catabolise it rapidly through their own expression of intracellular arginase- $2^{169}$. Boosting extracellular supplies of arginine, or inhibiting its catabolism by arginase, might enhance responding HBV-specific T cells in vivo, as it can in vitro ${ }^{167}$.

Our understanding of B cell defects in CHB is an exciting new area in which to identify therapeutic targets, but it currently lags behind that of T cells. The first ex vivo analyses of $B$ cells have supported this approach by revealing that HBsAg-specific populations persist in many donors with $\mathrm{CHB}$, providing some initial profiling to inform future in-depth studies ${ }^{23,25}$. The atypical memory $B$ cell fraction, which is expanded in $C H B$, over-expressed other regulatory molecules (for example, FCRL5, BTLA, CD32B) that might represent suitable targets as alternatives to PD1 ${ }^{170}$. B cells in $\mathrm{CHB}$ also had a signature indicative of impaired $\mathrm{T}$ cell help, suggesting that methods to boost defective $T_{F H}$ cells and to optimise the $B$ cell-T cell cross-talk shown in Figure 3, might enhance humoral immunity.

\section{[H2] Indirect approaches}

A number of other treatment strategies being tested or considered for $\mathrm{CHB}$ are expected to modulate adaptive immunity without targeting $T$ cells or B cells directly (Box 2, Figure 4).

\section{[H3] TLR agonists}

The oral TLR7 agonist GS-9620, postulated to boost dendritic cell priming, was able to boost expansion of functional HBV-specific T cells from patients with $\mathrm{CHB}$ undergoing in vivo treatment ${ }^{171}$. Although treatment with GS-9620 led to a simultaneous expansion of NK cells, HBV-specific T cells treated with the TLR7 agonist appeared more resistant to NK cellmediated removal, probably owing to TLR7-induced interferon stimulating genes ${ }^{172}$ that have been shown in mouse models of LCMV to protect T cells from NK cell deletion ${ }^{173}$. Despite these promising in vitro results, this TLR7 agonist failed to achieve HBsAg reduction in a phase II double blind trial in vivo as a single agent for $\mathrm{CHB}^{172}$. A better understanding of the mechanism of action of the TLR-7 agonist might enable further tailoring or combination usage, for example with a therapeutic vaccine. The TLR-8 agonist GS-9688, now in phase II trials for CHB, predominantly induces IL-12 and might therefore be able to harness HBVspecific CD8 T cells ${ }^{147,174}$, as detailed earlier. B cells also express several TLRs and could, 
therefore, be amenable to direct targeting through TLR-agonist-based therapies in CHB; the effects of TLR agonists on B cell responses need further investigation.

\section{[H3] HBV antigen reduction}

As excessive antigenic stimulation of antigen-specific T cells and B cells through their antigen receptors is thought to be a major mechanism leading to their exhaustion ${ }^{161,175} 176$, some recovery or protection of newly generated responses might be achievable if such triggering can be substantially reduced. A reduction in hepatocyte production and processing of HBV antigens resulting in reduced presentation of HBV peptides by MHC would be required to limit over-stimulation of cognate T cells through their TCR. This strategy might be attainable with new direct antiviral approaches such as liver-targeted RNA interference to degrade HBV transcripts ${ }^{7,14}$, although it could be less effective in $\mathrm{HBeAg}$ negative patients, in whom integrated DNA might represent a major source of $\mathrm{HBsAg}^{14}$. Even if HBV viral antigen presentation could be eliminated, $\mathrm{T}$ cell restoration might be limited by residual epigenetic 'scars' described in mouse models of T cell exhaustion ${ }^{177,178}$. Consistent with the difficulty of restoring $T$ cells after complete viral antigen removel, data from patients who have cleared HCV after direct-acting antiviral treatment have revealed persistence of a subset of antigen-independent memory-like TCF1 ${ }^{+} \mathrm{T}$ cells, but these only

exhibit partial functional recovery ${ }^{132,177,179}$. However, in the event that hepatocyte HBV antigen presentation could be reduced, a therapeutic vaccine could then be used to prime new HBV-specific $T$ cell responses that would be protected from over-stimulation.

In the case of B cells, it is likely that the exceptionally high levels of HBsAg in the liver and circulation, from both HBV virions and subviral particles, contribute to the atypical phenotype and signalling defects defined for HBsAg-specific $B$ cells ${ }^{23,25}$. Although a simple relationship between circulating $\mathrm{HBsAg}$ titres and $\mathrm{HBsAg}$-specific $\mathrm{B}$ cell exhaustion has not been observed ${ }^{23,25}$, data from malaria and HIV support the role of antigens in driving analogous $B$ cell exhaustion ${ }^{176}$. Potential therapeutic approaches to specifically reduce levels of HBsAg available to bind B cells include its sequestration by monoclonal antibodies (discussed later), or the inhibition of its release from hepatocytes by nucleic acid polymers ${ }^{180}$. Both approaches would reduce the over-stimulation of HBsAg-specific B cells through their BCR, but it remains to be seen if they would enable recovery of $B$ cell function, rather than simply un-masking pre-existing antibodies that are no longer overwhelmed by high circulating HBsAg levels.

\section{[H3] Treatment interruption}

Data have revealed that cessation or interruption of long-term nucleotide analogue treatment can accelerate $\mathrm{HBsAg}$ loss in some patients with $\mathrm{HBeAg}$-negative $\mathrm{CHB}^{181}$. Withdrawal of treatment is frequently associated with high rates of virological relapse and 
hepatic inflammation and, therefore, needs to be carried out with caution. However, some patients who are able to control HBV following treatment cessation are characterised by increased frequencies of HBV-specific T cells ${ }^{35,181-183}$. The mechanisms triggering such immune reconstitution remain obscure and predictive biological markers of patients that can safely and effectively stop antiviral therapy are needed. The capacity of treatment interruption to induce some immune restoration makes it a compelling starting point for additional intervention with immunotherapies that have been shown to be safe in patients with low viral load.

\section{[H1] Supplementation of adaptive immunity}

Even with combinations of the already described approaches it might prove difficult to rescue severely impaired endogenous immune responses in some patients with CHB. Supplementation with an exogenous source of HBV-specific adaptive immune effectors (derived from T cells or B cells, Box 2, Figure 4) circumvents this limitation, as it can provide a highly selective, targeted treatment without the bystander off-target effects that might occur when unleashing physiological constraints on endogenous immunity. The selective administration of specific exogenous effectors such as antibodies might additionally harness complementary components of the endogenous immune response, as discussed later.

\section{[H2] TCR-redirected T cells and CAR T cells}

Both TCR-redirected T cell and chimeric antigen receptor (CAR) T cell approaches involve genetically engineering patient-derived $T$ cells to direct them against HBV in adoptive cell therapy ${ }^{184,185}$. CAR T cells are transduced with an antibody-like receptor to recognise HBsAg on the surface of infected hepatocytes ${ }^{186,187}$, whereas TCR-redirected T cells respond to HBV peptides presented by MHC and are therefore specific for the donor HLA-type ${ }^{188}$. These adoptive $T$ cell therapies are showing exciting results in patients with haematological malignancies and solid cancers such as melanoma ${ }^{189}$. HBV-related HCC can harbour integrated HBV-DNA fragments that can encode for T cell epitopes; $T$ cells engineered to express TCRs specific for these epitopes have already been safely tested in 3 patients with HCC metastases ${ }^{190,191}$. T cells engineered to express HBV-specific TCRs or CARs have also shown potent antiviral potential in a preclinical model of chimeric humanised liver mice infected with HBV ${ }^{187,192,193 .}$

Several modifications have been developed recently to enhance the efficacy of TCRredirected T cells. CRISPR-Cas9-based knockdown of the endogenous TCR has been shown to enhance transduction and expression of the transferred TCR, and will also prevent mispairing, thereby abolishing the risk of generating new autoreactive specificities ${ }^{194}$. In addition to re-directing specificity, functional modifications can render the transferred $T$ cells better able to withstand the hostile liver environment. Using small interfering RNA 
knockdown of PD1 on human TCR-re-directed T cells increased their short-term cytotoxic capacity in a 3D model of $\mathrm{HBV}$-expressing $\mathrm{HCC}^{134}$. An alternative to lentiviral or retroviral transduction is mRNA electroporation of the TCR of interest, which means that responses will be short-lived, neccessitating repeated administration, but making initial testing safer ${ }^{195}$. mRNA electroporation can be carried out on resting cells and results in responses that are less cytotoxic and skewed towards non-cytolytic elimination of HBV through lymphotoxin- $\beta$-mediated induction of $A B O B E C 3^{60}$ (Figure 1,4 ).

In addition to safety concerns, it currently remains impractical to scale-up adoptive $T$ cell therapy for widespread clinical use in CHB because of the highly skilled laboratory personnel required, and the strict regulation and expense involved in transducing large numbers of cells in a Good Manufacturing Practice facility. TCR-redirected T cells need to be personalised to patient HLA and HBV genotypes, whereas CAR-T cells directed against HBsAg might be diverted or exhausted by the large amounts of circulating antigens in CHB. Thus, at present, adoptive cell therapy with CAR T cells or TCR-redirected T cells is best suited to selected cases of HBV-related HCC, which is currently being tested in phase I trials $^{195}$.

\section{[H2] Soluble TCRs}

Instead of relying on adoptive cell therapy, soluble TCRs directed against HBV-peptides or $\mathrm{MHC}$ ligands can be administered that bypass the need for ex vivo manipulation of T cells. These soluble TCRs can be affinity matured to have exceptionally high specificity ${ }^{196}$. Affinityenhanced soluble TCRs fused to anti-CD3 immune-mobilising monoclonal TCRs against viruses (ImmTAVs (Immunocore)) $)^{197}$ are being developed for HBV that will bind to, and direct, any CD3-expressing cells towards hepatocytes expressing the MHC or peptide complexes recognised by the TCR. As the liver contains a large fraction of unconventional CD3-expressing lymphocytes such as mucosal associated invariant T cells ${ }^{198}$, these might also be engaged by ImmTAVs. This approach therefore necessitates a better understanding of the potential effector functions of all intrahepatic CD3-expressing cell types.

\section{[H2] Therapeutic antibodies}

The development of therapeutic antibodies has shown promising results in a wide variety of disease settings, including when directed against HIV199, and it is a growing area of investigation for the treatment of CHB. Combinations of broadly neutralising antibodies capable of recognising multiple virus strains have shown success in human trials of HIV infection, in which they maintain long-term viral suppression and resistance to virus mutation 200,201 . More preliminary results suggest antibodies might also hold therapeutic potential in HBV. Early studies testing combinations of human monoclonal antibodies against HBsAg showed short-term viral suppression in models of chimpanzee HBV infection $^{202}$ and humans ${ }^{77,203}$. 
Next generation monoclonal antibodies display improved broadly neutralising potential against different HBV strains and escape mutants ${ }^{204,205}$ and have demonstrated potent antiviral activity, acting in vivo to reduce levels of HBsAg and HBV DNA in HBV-transgenic mice through Fc-dependant mechanisms ${ }^{206,207}$. Engagement of Fc-mediated phagocytosis was elegantly demonstrated, with the suppressive abilities of these antibodies inhibited when Fc-receptor binding was impeded through mutation of the Fc portion ${ }^{207}$. Through binding to circulating HBsAg and forming immune complexes, therapeutic antibodies might also form higher avidity interactions with FcRs, resulting in superior viral clearance through Fc-dependent phagocytosis ${ }^{206}$. To understand how to manipulate Fc-dependent antibody effector functions to their full therapeutic potential, it will be important to ascertain whether the potential for Fc-mediated protection is maintained in chronic infections. In chronic HCV, downregulated expression of FCR $\gamma$ RIII (CD16) by activated NK cells results in impaired ADCC-mediated killing of infected target cells, representing one possible mechanism underpinning viral persistence ${ }^{208}$.

In an analogous approach to ImmTAVs, genetic manipulation of therapeutic antibody constructs to recognise multiple domains (referred to as bispecific antibodies) might increase their efficacy against HBV by enabling them to simultaneously engage local effector cells. In situ delivery of plasmids encoding bi-specific antibodies that concurrently target $\mathrm{HBsAg}$ and CD3 have demonstrated potent, non-cytopathic antiviral activity in the liver of HBV mouse models, with the presence of the CD3-specific domain facilitating recruitment of non-specific $\mathrm{T}$ cells and resulting in a rapid and significant reduction in $\mathrm{HBsAg}^{209}$. Livertargeted generation or delivery of anti-HBs antibodies should reduce their sequestration by the large sink of circulating subviral particles and the resultant risk of immune complexmediated disease.

\section{[H1] Conclusions}

Advances in our understanding of some key features of HBV-specific T cell immunity have been accompanied by the first ex vivo analyses of HBsAg-specific B cells. Future studies will need to consider these two vital components of the adaptive immune response to HBV in parallel to better understand their cross-talk and potential for therapeutic targeting. A detailed understanding of the optimal transcriptional, epigenetic and metabolic wiring for antiviral efficacy will enable more precise manipulation. A number of therapeutic approaches are already available to boost or replace adaptive immunity, capitalising on the elegant precision of targeting that $B$ cell and $T$ cell antigen-specific receptors allow. It remains to be seen how tractable these targets will be in clinical practice. A major limitation will be the heterogeneity of $\mathrm{T}$ cell responsivity to such approaches that has already been demonstrated in vitro in patients infected with $\mathrm{HBV}$, and the high safety threshold required to test novel approaches in the setting of a chronic viral infection. New immunotherapies 
can be more easily tested in the setting of HBV-related HCC and can be advanced towards application in HBV by developing predictors of responsiveness.

1 Tassopoulos, N. C. et al. Natural history of acute hepatitis B surface antigen-positive hepatitis in Greek adults. Gastroenterology 92, 1844-1850, doi:10.1016/00165085(87)90614-7 (1987).

2 Cooke, G. S. et al. Accelerating the elimination of viral hepatitis: a Lancet Gastroenterology \& Hepatology Commission. Lancet Gastroenterol Hepatol 4, 135184, doi:10.1016/S2468-1253(18)30270-X (2019).

3 Lazarus, J. V. et al. The hepatitis B epidemic and the urgent need for cure preparedness. Nat Rev Gastroenterol Hepatol 15, 517-518, doi:10.1038/s41575-0180041-6 (2018).

4 Revill, P. A. et al. A global scientific strategy to cure hepatitis B. Lancet Gastroenterol Hepatol 4, 545-558, doi:10.1016/S2468-1253(19)30119-0 (2019).

5 Seto, W. K., Lo, Y. R., Pawlotsky, J. M. \& Yuen, M. F. Chronic hepatitis B virus infection. Lancet 392, 2313-2324, doi:10.1016/S0140-6736(18)31865-8 (2018).

6 Levrero, M., Subic, M., Villeret, F. \& Zoulim, F. Perspectives and limitations for nucleo(t)side analogs in future HBV therapies. Curr Opin Virol 30, 80-89, doi:10.1016/j.coviro.2018.04.006 (2018).

$7 \quad$ Xia, Y. \& Liang, T. J. Development of Direct-acting Antiviral and Host-targeting Agents for Treatment of Hepatitis B Virus Infection. Gastroenterology 156, 311-324, doi:10.1053/j.gastro.2018.07.057 (2019).

8 Brahmania, M., Feld, J., Arif, A. \& Janssen, H. L. New therapeutic agents for chronic hepatitis B. Lancet Infect Dis 16, e10-21, doi:10.1016/S1473-3099(15)00436-3 (2016).

9 Ko, C., Michler, T. \& Protzer, U. Novel viral and host targets to cure hepatitis B. Curr Opin Virol 24, 38-45, doi:10.1016/j.coviro.2017.03.019 (2017).

10 Asabe, S. et al. The size of the viral inoculum contributes to the outcome of hepatitis B virus infection. J Virol 83, 9652-9662 (2009).

11 Rehermann, B., Ferrari, C., Pasquinelli, C. \& Chisari, F. V. The hepatitis B virus persists for decades after patients' recovery from acute viral hepatitis despite active maintenance of a cytotoxic T-lymphocyte response. Nat Med 2, 1104-1108 (1996).

12 Lok, A. S., Zoulim, F., Dusheiko, G. \& Ghany, M. G. Hepatitis B cure: From discovery to regulatory approval. J Hepatol 67, 847-861, doi:10.1016/j.jhep.2017.05.008 (2017).

13 Mason, W. S. et al. HBV DNA Integration and Clonal Hepatocyte Expansion in Chronic Hepatitis B Patients Considered Immune Tolerant. Gastroenterology 151, 986-998 e984, doi:10.1053/j.gastro.2016.07.012 (2016).

14 Wooddell, C. I. et al. RNAi-based treatment of chronically infected patients and chimpanzees reveals that integrated hepatitis B virus DNA is a source of $\mathrm{HBsAg}$. Sci Transl Med 9, doi:10.1126/scitransImed.aan0241 (2017).

15 McLane, L. M., Abdel-Hakeem, M. S. \& Wherry, E. J. CD8 T Cell Exhaustion During Chronic Viral Infection and Cancer. Annu Rev Immunol 37, 457-495, doi:10.1146/annurev-immunol-041015-055318 (2019).

16 Hashimoto, M. et al. CD8 T Cell Exhaustion in Chronic Infection and Cancer: Opportunities for Interventions. Annu Rev Med 69, 301-318, doi:10.1146/annurevmed-012017-043208 (2018). 
17 Maini, M. K. \& Gehring, A. J. The role of innate immunity in the immunopathology and treatment of HBV infection. J Hepatol 64, S60-70, doi:10.1016/j.jhep.2016.01.028 (2016).

18 Maini, M. K. \& Pallett, L. J. Defective T-cell immunity in hepatitis B virus infection: why therapeutic vaccination needs a helping hand. Lancet Gastroenterol Hepatol 3, 192-202, doi:10.1016/S2468-1253(18)30007-4 (2018).

19 Suslov, A., Wieland, S. \& Menne, S. Modulators of innate immunity as novel therapeutics for treatment of chronic hepatitis B. Curr Opin Virol 30, 9-17, doi:10.1016/j.coviro.2018.01.008 (2018).

20 Bertoletti, A. \& Ferrari, C. Adaptive immunity in HBV infection. J Hepatol 64, S71-83, doi:10.1016/j.jhep.2016.01.026 (2016).

21 Shin, E. C., Sung, P. S. \& Park, S. H. Immune responses and immunopathology in acute and chronic viral hepatitis. Nat Rev Immunol 16, 509-523, doi:10.1038/nri.2016.69 (2016).

22 Loomba, R. \& Liang, T. J. Hepatitis B Reactivation Associated With Immune Suppressive and Biological Modifier Therapies: Current Concepts, Management Strategies, and Future Directions. Gastroenterology 152, 1297-1309, doi:10.1053/j.gastro.2017.02.009 (2017).

23 Burton, A. R. et al. Circulating and intrahepatic antiviral B cells are defective in hepatitis B. J Clin Invest 128, 4588-4603, doi:10.1172/JCI121960 (2018).

24 Neumann-Haefelin, C. \& Thimme, R. Entering the spotlight: hepatitis B surface antigen-specific B cells. J Clin Invest 128, 4257-4259, doi:10.1172/JCl124098 (2018).

25 Salimzadeh, L. et al. PD-1 blockade partially recovers dysfunctional virus-specific B cells in chronic hepatitis B infection. J Clin Invest 128, 4573-4587, doi:10.1172/JCl121957 (2018).

26 Cannon, J. P., Haire, R. N., Rast, J. P. \& Litman, G. W. The phylogenetic origins of the antigen-binding receptors and somatic diversification mechanisms. Immunol Rev 200, 12-22, doi:10.1111/j.0105-2896.2004.00166.x (2004).

27 Bertoletti, A. et al. Cytotoxic T lymphocyte response to a wild type hepatitis B virus epitope in patients chronically infected by variant viruses carrying substitutions within the epitope. J Exp Med 180, 933-943 (1994).

28 Bertoletti, A. et al. Natural variants of cytotoxic epitopes are T-cell receptor antagonists for antiviral cytotoxic T cells. Nature 369, 407-410, doi:10.1038/369407a0 (1994).

29 Rehermann, B., Pasquinelli, C., Mosier, S. M. \& Chisari, F. V. Hepatitis B virus (HBV) sequence variation of cytotoxic $T$ lymphocyte epitopes is not common in patients with chronic HBV infection. J Clin Invest 96, 1527-1534, doi:10.1172/JCI118191 (1995).

30 Rehermann, B. \& Thimme, R. Insights From Antiviral Therapy Into Immune Responses to Hepatitis B and C Virus Infection. Gastroenterology, doi:10.1053/j.gastro.2018.08.061 (2018).

31 Desmond, C. P. et al. Viral adaptation to host immune responses occurs in chronic hepatitis B virus (HBV) infection, and adaptation is greatest in HBV e antigennegative disease. J Virol 86, 1181-1192, doi:10.1128/JVI.05308-11 (2012).

32 Kefalakes, H. et al. Adaptation of the hepatitis B virus core protein to CD8(+) T-cell selection pressure. Hepatology 62, 47-56, doi:10.1002/hep.27771 (2015). 
33 Maini, M. K. et al. Direct ex vivo analysis of hepatitis B virus-specific CD8(+) T cells associated with the control of infection. Gastroenterology 117, 1386-1396 (1999).

34 Webster, G. J. et al. Longitudinal analysis of CD8+ T cells specific for structural and nonstructural hepatitis B virus proteins in patients with chronic hepatitis B: implications for immunotherapy. J Virol 78, 5707-5719 (2004).

35 Rivino, L. et al. Hepatitis B virus-specific T cells associate with viral control upon nucleos(t)ide-analogue therapy discontinuation. J Clin Invest 128, 668-681, doi:10.1172/JCI92812 (2018).

36 Boni, C. et al. Characterization of hepatitis B virus (HBV)-specific T-cell dysfunction in chronic HBV infection. J Virol 81, 4215-4225 (2007).

37 Park, J. J. et al. Hepatitis B Virus--Specific and Global T-Cell Dysfunction in Chronic Hepatitis B. Gastroenterology 150, 684-695 e685, doi:10.1053/j.gastro.2015.11.050 (2016).

38 Schuch, A. et al. Phenotypic and functional differences of HBV core-specific versus HBV polymerase-specific CD8+ T cells in chronically HBV-infected patients with low viral load. Gut, doi:10.1136/gutjnl-2018-316641 (2019).

39 Hoogeveen, R. C. et al. Phenotype and function of HBV-specific T cells is determined by the targeted epitope in addition to the stage of infection. Gut, doi:10.1136/gutjnl2018-316644 (2018).

40 Khakpoor, A. et al. Spatio-temporal differences in presentation of CD8 T cell epitopes during HBV infection. J Virol, doi:10.1128/JVI.01457-18 (2018).

41 Gerlich, W. H. Medical virology of hepatitis B: how it began and where we are now. Virol J 10, 239, doi:10.1186/1743-422X-10-239 (2013).

42 Hoofnagle, J. H., Gerety, R. J. \& Barker, L. F. Antibody to hepatitis-B-virus core in man. Lancet 2, 869-873 (1973).

43 Pignatelli, M. et al. Cytotoxic T-cell responses to the nucleocapsid proteins of HBV in chronic hepatitis. Evidence that antibody modulation may cause protracted infection. J Hepatol 4, 15-21 (1987).

44 Farci, P. et al. B cell gene signature with massive intrahepatic production of antibodies to hepatitis $B$ core antigen in hepatitis $B$ virus-associated acute liver failure. Proc Natl Acad Sci U S A 107, 8766-8771, doi:10.1073/pnas.1003854107 (2010).

45 Chen, Z. et al. Role of humoral immunity against hepatitis $B$ virus core antigen in the pathogenesis of acute liver failure. Proc Natl Acad Sci U S A 115, E11369-E11378, doi:10.1073/pnas.1809028115 (2018).

46 Yuan, Q. et al. Total Hepatitis B Core Antigen Antibody, a Quantitative Non-Invasive Marker of Hepatitis B Virus Induced Liver Disease. PLoS One 10, e0130209, doi:10.1371/journal.pone.0130209 (2015).

47 Yuen, M. F. et al. Hepatitis B virus infection. Nat Rev Dis Primers 4, 18035, doi:10.1038/nrdp.2018.35 (2018).

48 Beasley, R. P. et al. Hepatitis B immune globulin (HBIG) efficacy in the interruption of perinatal transmission of hepatitis $B$ virus carrier state. Initial report of a randomised double-blind placebo-controlled trial. Lancet 2, 388-393 (1981).

49 Shouval, D. \& Samuel, D. Hepatitis B immune globulin to prevent hepatitis B virus graft reinfection following liver transplantation: a concise review. Hepatology 32, 1189-1195, doi:10.1053/jhep.2000.19789 (2000). 
50 Tian, C. et al. Use of ELISpot assay to study HBs-specific B cell responses in vaccinated and HBV infected humans. Emerg Microbes Infect 7, 16, doi:10.1038/s41426-018-0034-0 (2018).

$51 \mathrm{Xu}, \mathrm{X}$. et al. Reversal of B-cell hyperactivation and functional impairment is associated with HBsAg seroconversion in chronic hepatitis B patients. Cell Mol Immunol 12, 309-316, doi:10.1038/cmi.2015.25 (2015).

52 Guidotti, L. G. \& Chisari, F. V. Immunobiology and pathogenesis of viral hepatitis. Annu Rev Pathol 1, 23-61 (2006).

53 Guidotti, L. G., Isogawa, M. \& Chisari, F. V. Host-virus interactions in hepatitis B virus infection. Curr Opin Immunol 36, 61-66, doi:10.1016/j.coi.2015.06.016 (2015).

54 Thimme, R. et al. CD8(+) T cells mediate viral clearance and disease pathogenesis during acute hepatitis B virus infection. J Virol 77, 68-76 (2003).

55 Guidotti, L. G. et al. Intracellular inactivation of the hepatitis B virus by cytotoxic T lymphocytes. Immunity 4, 25-36 (1996).

56 Hoh, A. et al. Hepatitis B Virus-Infected HepG2hNTCP Cells Serve as a Novel Immunological Tool To Analyze the Antiviral Efficacy of CD8+ T Cells In Vitro. J Virol 89, 7433-7438, doi:10.1128/JVI.00605-15 (2015).

57 Phillips, S. et al. CD8(+) T cell control of hepatitis B virus replication: direct comparison between cytolytic and noncytolytic functions. J Immunol 184, 287-295, doi:10.4049/jimmunol.0902761 (2010).

58 Xia, Y. et al. Interferon-gamma and Tumor Necrosis Factor-alpha Produced by T Cells Reduce the HBV Persistence Form, cccDNA, Without Cytolysis. Gastroenterology 150, 194-205, doi:10.1053/j.gastro.2015.09.026 (2016).

59 Lucifora, J. et al. Specific and nonhepatotoxic degradation of nuclear hepatitis B virus cccDNA. Science 343, 1221-1228, doi:10.1126/science.1243462 (2014).

60 Koh, S. et al. Nonlytic Lymphocytes Engineered to Express Virus-Specific T-Cell Receptors Limit HBV Infection by Activating APOBEC3. Gastroenterology, doi:10.1053/j.gastro.2018.03.027 (2018).

61 Corti, D. \& Lanzavecchia, A. Broadly neutralizing antiviral antibodies. Annu Rev Immunol 31, 705-742, doi:10.1146/annurev-immunol-032712-095916 (2013).

62 Hangartner, L., Zinkernagel, R. M. \& Hengartner, H. Antiviral antibody responses: the two extremes of a wide spectrum. Nat Rev Immunol 6, 231-243, doi:10.1038/nri1783 (2006).

63 Cerino, A., Bremer, C. M., Glebe, D. \& Mondelli, M. U. A Human Monoclonal Antibody against Hepatitis B Surface Antigen with Potent Neutralizing Activity. PLoS One 10, e0125704, doi:10.1371/journal.pone.0125704 (2015).

64 Glebe, D. et al. Pre-s1 antigen-dependent infection of Tupaia hepatocyte cultures with human hepatitis B virus. J Virol 77, 9511-9521 (2003).

$65 \mathrm{Ni}, \mathrm{Y}$. et al. Hepatitis B and D viruses exploit sodium taurocholate co-transporting polypeptide for species-specific entry into hepatocytes. Gastroenterology 146, 10701083, doi:10.1053/j.gastro.2013.12.024 (2014).

66 Yan, H. et al. Sodium taurocholate cotransporting polypeptide is a functional receptor for human hepatitis B and D virus. Elife 1, e00049, doi:10.7554/eLife.00049 (2012).

67 Urban, S., Bartenschlager, R., Kubitz, R. \& Zoulim, F. Strategies to inhibit entry of HBV and HDV into hepatocytes. Gastroenterology 147, 48-64, doi:10.1053/j.gastro.2014.04.030 (2014). 
68 Petersen, J. et al. Prevention of hepatitis B virus infection in vivo by entry inhibitors derived from the large envelope protein. Nat Biotechnol 26, 335-341, doi:10.1038/nbt1389 (2008).

$69 \mathrm{Tu}, \mathrm{T}$. \& Urban, S. Virus entry and its inhibition to prevent and treat hepatitis B and hepatitis D virus infections. Curr Opin Virol 30, 68-79, doi:10.1016/j.coviro.2018.04.004 (2018).

70 Sureau, C. \& Salisse, J. A conformational heparan sulfate binding site essential to infectivity overlaps with the conserved hepatitis B virus a-determinant. Hepatology 57, 985-994, doi:10.1002/hep.26125 (2013).

71 Gerlich, W. H. The enigma of concurrent hepatitis B surface antigen (HBsAg) and antibodies to HBsAg. Clin Infect Dis 44, 1170-1172, doi:10.1086/513296 (2007).

72 Madalinski, K., Burczynska, B., Heermann, K. H., Uy, A. \& Gerlich, W. H. Analysis of viral proteins in circulating immune complexes from chronic carriers of hepatitis $B$ virus. Clin Exp Immunol 84, 493-500 (1991).

73 Hessell, A. J. et al. Fc receptor but not complement binding is important in antibody protection against HIV. Nature 449, 101-104, doi:10.1038/nature06106 (2007).

74 Lu, L. L., Suscovich, T. J., Fortune, S. M. \& Alter, G. Beyond binding: antibody effector functions in infectious diseases. Nat Rev Immunol 18, 46-61, doi:10.1038/nri.2017.106 (2018).

75 Chu, C. M. \& Liaw, Y. F. Intrahepatic distribution of hepatitis B surface and core antigens in chronic hepatitis $B$ virus infection. Hepatocyte with cytoplasmic/membranous hepatitis B core antigen as a possible target for immune hepatocytolysis. Gastroenterology 92, 220-225 (1987).

76 Ray, M. B. et al. Distribution patterns of hepatitis B surface antigen (HBsAg) in the liver of hepatitis patients. J Clin Pathol 29, 94-100 (1976).

77 Neumann, A. U. et al. Novel mechanism of antibodies to hepatitis B virus in blocking viral particle release from cells. Hepatology 52, 875-885, doi:10.1002/hep.23778 (2010).

78 Schilling, R. et al. Endocytosis of hepatitis B immune globulin into hepatocytes inhibits the secretion of hepatitis B virus surface antigen and virions. J Virol 77, 88828892 (2003).

79 Bournazos, S. \& Ravetch, J. V. Fcgamma Receptor Function and the Design of Vaccination Strategies. Immunity 47, 224-233, doi:10.1016/j.immuni.2017.07.009 (2017).

80 Liu, H. et al. Immuno-potentiating pathway of HBsAg-HBIG immunogenic complex visualized. Hum Vaccin Immunother 12, 77-84, doi:10.1080/21645515.2015.1072660 (2016).

81 Shen, P. \& Fillatreau, S. Antibody-independent functions of B cells: a focus on cytokines. Nat Rev Immunol 15, 441-451, doi:10.1038/nri3857 (2015).

82 Duddy, M. E., Alter, A. \& Bar-Or, A. Distinct profiles of human B cell effector cytokines: a role in immune regulation? J Immunol 172, 3422-3427 (2004).

83 Bouezzedine, F., Fardel, O. \& Gripon, P. Interleukin 6 inhibits HBV entry through NTCP down regulation. Virology 481, 34-42, doi:10.1016/j.virol.2015.02.026 (2015).

84 Hosel, M. et al. Not interferon, but interleukin-6 controls early gene expression in hepatitis B virus infection. Hepatology 50, 1773-1782 (2009). 
85 Palumbo, G. A. et al. IL6 Inhibits HBV Transcription by Targeting the Epigenetic Control of the Nuclear cccDNA Minichromosome. PLoS One 10, e0142599, doi:10.1371/journal.pone.0142599 (2015).

86 Karnowski, A. et al. B and T cells collaborate in antiviral responses via IL-6, IL-21, and transcriptional activator and coactivator, Oct2 and OBF-1. J Exp Med 209, 2049-2064, doi:10.1084/jem.20111504 (2012).

87 Harker, J. A., Lewis, G. M., Mack, L. \& Zuniga, E. I. Late interleukin-6 escalates T follicular helper cell responses and controls a chronic viral infection. Science 334, 825-829, doi:10.1126/science.1208421 (2011).

88 Crotty, S. A brief history of T cell help to B cells. Nat Rev Immunol 15, 185-189, doi:10.1038/nri3803 (2015).

89 Milich, D. R. \& McLachlan, A. The nucleocapsid of hepatitis B virus is both a T-cellindependent and a T-cell-dependent antigen. Science 234, 1398-1401 (1986).

90 Penna, A. et al. Long-lasting memory $T$ cell responses following self-limited acute hepatitis B. J Clin Invest 98, 1185-1194 (1996).

91 Raziorrouh, B. et al. Inhibitory phenotype of HBV-specific CD4+ T-cells is characterized by high PD-1 expression but absent coregulation of multiple inhibitory molecules. PLoS One 9, e105703, doi:10.1371/journal.pone.0105703 (2014).

92 Linterman, M. A. et al. Foxp3+ follicular regulatory T cells control the germinal center response. Nat Med 17, 975-982, doi:10.1038/nm.2425 (2011).

93 Dusheiko, G. M., Hoofnagle, J. H., Cooksley, W. G., James, S. P. \& Jones, E. A. Synthesis of antibodies to hepatitis B virus by cultured lymphocytes from chronic hepatitis B surface antigen carriers. J Clin Invest 71, 1104-1113 (1983).

94 Wang, R., Xie, R. \& Song, Z. Circulating regulatory Tfh cells are enriched in patients with chronic hepatitis $B$ infection and induce the differentiation of regulatory $B$ cells. Exp Cell Res 365, 171-176, doi:10.1016/j.yexcr.2018.02.031 (2018).

95 Wang, X. et al. Dysregulated Response of Follicular Helper T cells to Hepatitis B Surface Antigen Promotes HBV Persistence in Mice and Associates With Outcomes of Patients. Gastroenterology, doi:10.1053/j.gastro.2018.03.021 (2018).

96 Wu, X. et al. Increased Circulating Follicular Regulatory T-Like Cells May Play a Critical Role in Chronic Hepatitis B Virus Infection and Disease Progression. Viral Immunol 31, 379-388, doi:10.1089/vim.2017.0171 (2018).

97 Milich, D. R. et al. Role of B cells in antigen presentation of the hepatitis B core. Proc Natl Acad Sci U S A 94, 14648-14653 (1997).

98 Whitacre, D. C., Lee, B. O. \& Milich, D. R. Use of hepadnavirus core proteins as vaccine platforms. Expert Rev Vaccines 8, 1565-1573, doi:10.1586/erv.09.121 (2009).

99 Lazdina, U. et al. Priming of cytotoxic T cell responses to exogenous hepatitis B virus core antigen is B cell dependent. J Gen Virol 84, 139-146, doi:10.1099/vir.0.18678-0 (2003).

100 Barnaba, V., Franco, A., Alberti, A., Benvenuto, R. \& Balsano, F. Selective killing of hepatitis $B$ envelope antigen-specific $B$ cells by class I-restricted, exogenous antigenspecific T lymphocytes. Nature 345, 258-260 (1990).

101 Das, A. et al. IL-10-producing regulatory B cells in the pathogenesis of chronic hepatitis B virus infection. J Immunol 189, 3925-3935, doi:10.4049/jimmunol.1103139 (2012). 
102 Hawke, S., Stevenson, P. G., Freeman, S. \& Bangham, C. R. Long-term persistence of activated cytotoxic $T$ lymphocytes after viral infection of the central nervous system. J Exp Med 187, 1575-1582 (1998).

103 Mueller, S. N. \& Mackay, L. K. Tissue-resident memory T cells: local specialists in immune defence. Nat Rev Immunol 16, 79-89, doi:10.1038/nri.2015.3 (2016).

104 Rosato, P. C., Beura, L. K. \& Masopust, D. Tissue resident memory T cells and viral immunity. Curr Opin Virol 22, 44-50, doi:10.1016/j.coviro.2016.11.011 (2017).

105 Pallett, L. J. et al. IL-2high tissue-resident T cells in the human liver: Sentinels for hepatotropic infection. J Exp Med 214, 1567-1580, doi:10.1084/jem.20162115 (2017).

106 Maini, M. K. et al. The role of virus-specific CD8(+) cells in liver damage and viral control during persistent hepatitis B virus infection. J Exp Med 191, 1269-1280 (2000).

107 Moyron-Quiroz, J. E. et al. Role of inducible bronchus associated lymphoid tissue (iBALT) in respiratory immunity. Nat Med 10, 927-934, doi:10.1038/nm1091 (2004).

108 Murakami, J. et al. Functional B-cell response in intrahepatic lymphoid follicles in chronic hepatitis C. Hepatology 30, 143-150, doi:10.1002/hep.510300107 (1999).

109 Adachi, Y. et al. Distinct germinal center selection at local sites shapes memory B cell response to viral escape. J Exp Med 212, 1709-1723, doi:10.1084/jem.20142284 (2015).

110 Lefkowitch, J. H. et al. Pathological diagnosis of chronic hepatitis C: a multicenter comparative study with chronic hepatitis B. The Hepatitis Interventional Therapy Group. Gastroenterology 104, 595-603 (1993).

$111 \mathrm{Li}, \mathrm{L}$. et al. Anti-HBV response to toll-like receptor 7 agonist GS-9620 is associated with intrahepatic aggregates of $\mathrm{T}$ cells and B cells. J Hepatol 68, 912-921, doi:10.1016/j.jhep.2017.12.008 (2018).

112 Gill, U. S., Pallett, L. J., Kennedy, P. T. F. \& Maini, M. K. Liver sampling: a vital window into HBV pathogenesis on the path to functional cure. Gut 67, 767-775, doi:10.1136/gutjnl-2017-314873 (2018).

113 Gill, U. S. et al. Fine needle aspirates comprehensively sample intrahepatic immunity. Gut, doi:10.1136/gutjnl-2018-317071 (2018).

114 Maini, M. K. \& Bertoletti, A. How can the cellular immune response control hepatitis B virus replication? J Viral Hepat 7, 321-326 (2000).

115 Bertoletti, A. \& Maini, M. K. Protection or damage: a dual role for the virus-specific cytotoxic T lymphocyte response in hepatitis B and C infection? Curr Opin Immunol 12, 403-408 (2000).

116 Allweiss, L. et al. Proliferation of primary human hepatocytes and prevention of hepatitis B virus reinfection efficiently deplete nuclear cccDNA in vivo. Gut 67, 542552, doi:10.1136/gutjnl-2016-312162 (2018).

117 Zong, L. et al. Breakdown of adaptive immunotolerance induces hepatocellular carcinoma in HBsAg-tg mice. Nat Commun 10, 221, doi:10.1038/s41467-018-08096-8 (2019).

118 Lim, S. G., Agcaoili, J., De Souza, N. N. A. \& Chan, E. Therapeutic vaccination for chronic hepatitis B: A systematic review and meta-analysis. J Viral Hepat 26, 803817, doi:10.1111/jvh.13085 (2019). 
119 Michel, M. L., Deng, Q. \& Mancini-Bourgine, M. Therapeutic vaccines and immunebased therapies for the treatment of chronic hepatitis $B$ : perspectives and challenges. J Hepatol 54, 1286-1296, doi:10.1016/j.jhep.2010.12.031 (2011).

120 Dembek, C., Protzer, U. \& Roggendorf, M. Overcoming immune tolerance in chronic hepatitis B by therapeutic vaccination. Curr Opin Virol 30, 58-67, doi:10.1016/j.coviro.2018.04.003 (2018).

121 Kosinska, A. D., Bauer, T. \& Protzer, U. Therapeutic vaccination for chronic hepatitis B. Curr Opin Virol 23, 75-81, doi:10.1016/j.coviro.2017.03.011 (2017).

$122 \mathrm{Ha}, \mathrm{S}$. J. et al. Enhancing therapeutic vaccination by blocking PD-1-mediated inhibitory signals during chronic infection. J Exp Med 205, 543-555, doi:10.1084/jem.20071949 (2008).

123 Liu, J. et al. Enhancing virus-specific immunity in vivo by combining therapeutic vaccination and PD-L1 blockade in chronic hepadnaviral infection. PLoS Pathog 10, e1003856, doi:10.1371/journal.ppat.1003856 (2014).

124 Fisicaro, P. et al. Anti-Viral Intrahepatic T-Cell Responses can be Restored by Blocking Programmed Death-1 Pathway in Chronic Hepatitis B. Gastroenterology 138, 682693 (2009).

125 Isogawa, M., Furuichi, Y. \& Chisari, F. V. Oscillating CD8(+) T cell effector functions after antigen recognition in the liver. Immunity 23, 53-63 (2005).

126 Iwai, Y., Terawaki, S., Ikegawa, M., Okazaki, T. \& Honjo, T. PD-1 inhibits antiviral immunity at the effector phase in the liver. J Exp Med 198, 39-50 (2003).

127 El-Khoueiry, A. B. et al. Nivolumab in patients with advanced hepatocellular carcinoma (CheckMate 040): an open-label, non-comparative, phase $1 / 2$ dose escalation and expansion trial. Lancet 389, 2492-2502, doi:10.1016/S01406736(17)31046-2 (2017).

128 Gane, E. et al. Anti-PD-1 Blockade with Nivolumab with and without Therapeutic Vaccination for Virally Suppressed Chronic Hepatitis B: A Pilot Study. J Hepatol, doi:10.1016/j.jhep.2019.06.028 (2019).

129 Bengsch, B. et al. Epigenomic-Guided Mass Cytometry Profiling Reveals DiseaseSpecific Features of Exhausted CD8 T Cells. Immunity 48, 1029-1045 e1025, doi:10.1016/j.immuni.2018.04.026 (2018).

130 Utzschneider, D. T. et al. Active Maintenance of T Cell Memory in Acute and Chronic Viral Infection Depends on Continuous Expression of FOXO1. Cell Rep 22, 3454-3467, doi:10.1016/j.celrep.2018.03.020 (2018).

131 Utzschneider, D. T. et al. T cells maintain an exhausted phenotype after antigen withdrawal and population reexpansion. Nat Immunol 14, 603-610, doi:10.1038/ni.2606 (2013).

132 Wieland, D. et al. TCF1(+) hepatitis C virus-specific CD8(+) T cells are maintained after cessation of chronic antigen stimulation. Nat Commun 8, 15050, doi:10.1038/ncomms15050 (2017).

133 Kumar, B. V. et al. Human Tissue-Resident Memory T Cells Are Defined by Core Transcriptional and Functional Signatures in Lymphoid and Mucosal Sites. Cell Rep 20, 2921-2934, doi:10.1016/j.celrep.2017.08.078 (2017).

134 Otano, I. et al. Molecular Recalibration of PD-1+ Antigen-Specific T Cells from Blood and Liver. Mol Ther 26, 2553-2566, doi:10.1016/j.ymthe.2018.08.013 (2018). 
135 Odorizzi, P. M., Pauken, K. E., Paley, M. A., Sharpe, A. \& Wherry, E. J. Genetic absence of PD-1 promotes accumulation of terminally differentiated exhausted CD8+ T cells. J Exp Med 212, 1125-1137, doi:10.1084/jem.20142237 (2015).

136 Nebbia, G. et al. Upregulation of the Tim-3/galectin-9 pathway of T cell exhaustion in chronic hepatitis B virus infection. PLoS One 7, e47648, doi:10.1371/journal.pone.0047648 (2012).

137 Schurich, A. et al. Role of the co-inhibitory receptor CTLA-4 on apoptosis-prone CD8 T cells in persistent HBV infection. Hepatology 53, 1494-1503 (2011).

138 Inarrairaegui, M., Melero, I. \& Sangro, B. Immunotherapy of Hepatocellular Carcinoma: Facts and Hopes. Clin Cancer Res 24, 1518-1524, doi:10.1158/10780432.CCR-17-0289 (2018).

139 Titanji, K. et al. Acute depletion of activated memory B cells involves the PD-1 pathway in rapidly progressing SIV-infected macaques. J Clin Invest 120, 3878-3890, doi:10.1172/JCl43271 (2010).

140 Barnett, B. E. et al. Cutting Edge: B Cell-Intrinsic T-bet Expression Is Required To Control Chronic Viral Infection. J Immunol 197, 1017-1022, doi:10.4049/jimmunol.1500368 (2016).

141 Knox, J. J. et al. T-bet+ B cells are induced by human viral infections and dominate the HIV gp140 response. JCI Insight 2, doi:10.1172/jci.insight.92943 (2017).

142 Rubtsova, K., Rubtsov, A. V., van Dyk, L. F., Kappler, J. W. \& Marrack, P. T-box transcription factor T-bet, a key player in a unique type of B-cell activation essential for effective viral clearance. Proc Natl Acad Sci U S A 110, E3216-3224, doi:10.1073/pnas.1312348110 (2013).

143 Naradikian, M. S., Hao, Y. \& Cancro, M. P. Age-associated B cells: key mediators of both protective and autoreactive humoral responses. Immunol Rev 269, 118-129, doi:10.1111/imr.12380 (2016).

144 Das, R. et al. Early B cell changes predict autoimmunity following combination immune checkpoint blockade. J Clin Invest 128, 715-720, doi:10.1172/JCI96798 (2018).

145 Micco, L. et al. Differential boosting of innate and adaptive antiviral responses during pegylated-interferon-alpha therapy of chronic hepatitis B. J Hepatol 58, 225-233, doi:10.1016/j.jhep.2012.09.029 (2013).

146 Penna, A. et al. Peginterferon-alpha does not improve early peripheral blood HBVspecific T-cell responses in HBeAg-negative chronic hepatitis. J Hepatol (2012).

147 Schurich, A. et al. The third signal cytokine IL-12 rescues the anti-viral function of exhausted HBV-specific CD8 T cells. PLoS Pathog 9, e1003208, doi:10.1371/journal.ppat.1003208 (2013).

148 Schurich, A. et al. Distinct Metabolic Requirements of Exhausted and Functional Virus-Specific CD8 T Cells in the Same Host. Cell Rep 16, 1243-1252, doi:10.1016/j.celrep.2016.06.078 (2016).

149 Fisicaro, P. et al. Targeting mitochondrial dysfunction can restore antiviral activity of exhausted HBV-specific CD8 T cells in chronic hepatitis B. Nat Med 23, 327-336, doi:10.1038/nm.4275 (2017).

150 Bengsch, B. et al. Bioenergetic Insufficiencies Due to Metabolic Alterations Regulated by the Inhibitory Receptor PD-1 Are an Early Driver of CD8(+) T Cell Exhaustion. Immunity 45, 358-373, doi:10.1016/j.immuni.2016.07.008 (2016). 
151 Scharping, N. E. et al. The Tumor Microenvironment Represses T Cell Mitochondrial Biogenesis to Drive Intratumoral T Cell Metabolic Insufficiency and Dysfunction. Immunity 45, 701-703, doi:10.1016/j.immuni.2016.08.009 (2016).

152 Lasek, W., Zagozdzon, R. \& Jakobisiak, M. Interleukin 12: still a promising candidate for tumor immunotherapy? Cancer Immunol Immunother 63, 419-435, doi:10.1007/s00262-014-1523-1 (2014).

153 Dunn, C. et al. Cytokines induced during chronic hepatitis B virus infection promote a pathway for NK cell-mediated liver damage. J Exp Med 204, 667-680, doi:10.1084/jem.20061287 (2007).

154 Rehermann, B. Pathogenesis of chronic viral hepatitis: differential roles of T cells and NK cells. Nat Med 19, 859-868, doi:10.1038/nm.3251 (2013).

155 Waggoner, S. N., Cornberg, M., Selin, L. K. \& Welsh, R. M. Natural killer cells act as rheostats modulating antiviral T cells. Nature 481, 394-398 (2012).

156 Waggoner, S. N. et al. Roles of natural killer cells in antiviral immunity. Curr Opin Virol 16, 15-23, doi:10.1016/j.coviro.2015.10.008 (2015).

157 Peppa, D. et al. Up-regulation of a death receptor renders antiviral T cells susceptible to NK cell-mediated deletion. J Exp Med 210, 99-114, doi:10.1084/jem.20121172 (2013).

158 Huang, W. C. et al. T Cells Infiltrating Diseased Liver Express Ligands for the NKG2D Stress Surveillance System. J Immunol 198, 1172-1182, doi:10.4049/jimmunol.1601313 (2017).

159 Boni, C. et al. Natural killer cell phenotype modulation and natural killer/T-cell interplay in nucleos(t)ide analogue-treated hepatitis e antigen-negative patients with chronic hepatitis B. Hepatology, doi:10.1002/hep.28155 (2015).

160 Andre, P. et al. Anti-NKG2A mAb Is a Checkpoint Inhibitor that Promotes Anti-tumor Immunity by Unleashing Both T and NK Cells. Cell 175, 1731-1743 e1713, doi:10.1016/j.cell.2018.10.014 (2018).

161 Wherry, E. J. \& Kurachi, M. Molecular and cellular insights into T cell exhaustion. Nat Rev Immunol 15, 486-499, doi:10.1038/nri3862 (2015).

162 Attanasio, J. \& Wherry, E. J. Costimulatory and Coinhibitory Receptor Pathways in Infectious Disease. Immunity 44, 1052-1068, doi:10.1016/j.immuni.2016.04.022 (2016).

163 Fisicaro, P., Boni, C., Barili, V., Laccabue, D. \& Ferrari, C. Strategies to overcome HBVspecific $T$ cell exhaustion: checkpoint inhibitors and metabolic re-programming. Curr Opin Virol 30, 1-8, doi:10.1016/j.coviro.2018.01.003 (2018).

164 Kelly, P. N. CD28 is a critical target for PD-1 blockade. Science 355, 1386, doi:10.1126/science.355.6332.1386-b (2017).

165 Bengsch, B., Martin, B. \& Thimme, R. Restoration of HBV-specific CD8+ T cell function by PD-1 blockade in inactive carrier patients is linked to T cell differentiation. J Hepatol 61, 1212-1219, doi:10.1016/j.jhep.2014.07.005 (2014).

166 Menk, A. V. et al. 4-1BB costimulation induces $T$ cell mitochondrial function and biogenesis enabling cancer immunotherapeutic responses. J Exp Med 215, 10911100, doi:10.1084/jem.20171068 (2018).

167 Pallett, L. J. et al. Metabolic regulation of hepatitis B immunopathology by myeloidderived suppressor cells. Nat Med 21, 591-600, doi:10.1038/nm.3856 (2015). 
168 Sandalova, E. et al. Increased levels of arginase in patients with acute hepatitis B suppress antiviral $T$ cells. Gastroenterology 143, 78-87 e73, doi:10.1053/j.gastro.2012.03.041 (2012).

169 Geiger, R. et al. L-Arginine Modulates T Cell Metabolism and Enhances Survival and Anti-tumor Activity. Cell 167, 829-842 e813, doi:10.1016/j.cell.2016.09.031 (2016).

170 Kardava, L. et al. Attenuation of HIV-associated human B cell exhaustion by siRNA downregulation of inhibitory receptors. J Clin Invest 121, 2614-2624, doi:10.1172/JCl45685 (2011).

171 Boni, C. et al. TLR7 Agonist Increases Responses of Hepatitis B Virus-Specific T Cells and Natural Killer Cells in Patients With Chronic Hepatitis B Treated With Nucleos(T)Ide Analogues. Gastroenterology 154, 1764-1777 e1767, doi:10.1053/j.gastro.2018.01.030 (2018).

172 Janssen, H. L. A. et al. Safety, efficacy and pharmacodynamics of vesatolimod (GS9620) in virally suppressed patients with chronic hepatitis B. J Hepatol 68, 431-440, doi:10.1016/j.jhep.2017.10.027 (2018).

173 Davidson, S., Maini, M. K. \& Wack, A. Disease-promoting effects of type I interferons in viral, bacterial, and coinfections. J Interferon Cytokine Res 35, 252-264, doi:10.1089/jir.2014.0227 (2015).

174 Kurktschiev, P. D. et al. Dysfunctional CD8+ T cells in hepatitis B and C are characterized by a lack of antigen-specific T-bet induction. J Exp Med 211, 20472059, doi:10.1084/jem.20131333 (2014).

175 Mueller, S. N. \& Ahmed, R. High antigen levels are the cause of T cell exhaustion during chronic viral infection. Proc Natl Acad Sci U S A 106, 8623-8628 (2009).

176 Portugal, S., Obeng-Adjei, N., Moir, S., Crompton, P. D. \& Pierce, S. K. Atypical memory B cells in human chronic infectious diseases: An interim report. Cell Immunol 321, 18-25, doi:10.1016/j.cellimm.2017.07.003 (2017).

177 Hofmann, M., Wieland, D., Pircher, H. \& Thimme, R. Memory vs memory-like: The different facets of CD8(+) T-cell memory in HCV infection. Immunol Rev 283, 232237, doi:10.1111/imr.12642 (2018).

178 Pauken, K. E. et al. Epigenetic stability of exhausted T cells limits durability of reinvigoration by PD-1 blockade. Science 354, 1160-1165, doi:10.1126/science.aaf2807 (2016).

179 Wieland, D., Hofmann, M. \& Thimme, R. Overcoming CD8+ T-Cell Exhaustion in Viral Hepatitis: Lessons from the Mouse Model and Clinical Perspectives. Dig Dis 35, 334338, doi:10.1159/000456584 (2017).

180 Bazinet, M. et al. Safety and efficacy of REP 2139 and pegylated interferon alfa-2a for treatment-naive patients with chronic hepatitis $B$ virus and hepatitis $D$ virus coinfection (REP 301 and REP 301-LTF): a non-randomised, open-label, phase 2 trial. Lancet Gastroenterol Hepatol 2, 877-889, doi:10.1016/S2468-1253(17)30288-1 (2017).

181 Moreno-Cubero, E. et al. Is it possible to stop nucleos(t)ide analogue treatment in chronic hepatitis B patients? World J Gastroenterol 24, 1825-1838, doi:10.3748/wjg.v24.i17.1825 (2018).

182 Rinker, F. et al. Hepatitis B virus-specific T cell responses after stopping nucleos(t)ide analogue therapy in HBeAg-negative chronic hepatitis B. J Hepatol 69, 584-593, doi:10.1016/j.jhep.2018.05.004 (2018). 
183 Berg, T. et al. Long-term response after stopping tenofovir disoproxil fumarate in non-cirrhotic HBeAg-negative patients - FINITE study. J Hepatol, doi:10.1016/j.jhep.2017.07.012 (2017).

184 Bertoletti, A. \& Rivino, L. Hepatitis B: future curative strategies. Curr Opin Infect Dis 27, 528-534, doi:10.1097/QCO.0000000000000110 (2014).

185 Gehring, A. \& Protzer, U. Targeting Innate and Adaptive Immune Responses to Cure Chronic HBV Infection. Gastroenterology, doi:10.1053/j.gastro.2018.10.032 (2018).

186 Bohne, F. et al. T cells redirected against hepatitis B virus surface proteins eliminate infected hepatocytes. Gastroenterology 134, 239-247, doi:10.1053/j.gastro.2007.11.002 (2008).

187 Krebs, K. et al. T cells expressing a chimeric antigen receptor that binds hepatitis B virus envelope proteins control virus replication in mice. Gastroenterology 145, 456465, doi:10.1053/j.gastro.2013.04.047 (2013).

188 Gehring, A. J. et al. Engineering virus-specific T cells that target HBV infected hepatocytes and hepatocellular carcinoma cell lines. J Hepatol 55, 103-110, doi:10.1016/j.jhep.2010.10.025 (2011).

189 Lim, W. A. \& June, C. H. The Principles of Engineering Immune Cells to Treat Cancer. Cell 168, 724-740, doi:10.1016/j.cell.2017.01.016 (2017).

190 Qasim, W. et al. Immunotherapy of HCC metastases with autologous T cell receptor redirected T cells, targeting HBsAg in a liver transplant patient. J Hepatol 62, 486491, doi:10.1016/j.jhep.2014.10.001 (2015).

191 Tan, A. T. et al. Use of Expression Profiles of HBV-DNA Integrated Into Genomes of Hepatocellular Carcinoma Cells to Select $T$ Cells for Immunotherapy. Gastroenterology 156, 1862-1876 e1869, doi:10.1053/j.gastro.2019.01.251 (2019).

192 Kah, J. et al. Lymphocytes transiently expressing virus-specific T cell receptors reduce hepatitis B virus infection. J Clin Invest 127, 3177-3188, doi:10.1172/JCI93024 (2017).

193 Wisskirchen, K. et al. T cell receptor grafting allows virological control of Hepatitis B virus infection. J Clin Invest 130, doi:10.1172/JCI120228 (2019).

194 Legut, M., Dolton, G., Mian, A. A., Ottmann, O. G. \& Sewell, A. K. CRISPR-mediated TCR replacement generates superior anticancer transgenic T cells. Blood 131, 311322, doi:10.1182/blood-2017-05-787598 (2018).

195 Koh, S. et al. A practical approach to immunotherapy of hepatocellular carcinoma using T cells redirected against hepatitis B virus. Mol Ther Nucleic Acids 2, e114, doi:10.1038/mtna.2013.43 (2013).

196 Oates, J., Hassan, N. J. \& Jakobsen, B. K. ImmTACs for targeted cancer therapy: Why, what, how, and which. Mol Immunol 67, 67-74, doi:10.1016/j.molimm.2015.01.024 (2015).

197 Yang, H. et al. Elimination of Latently HIV-infected Cells from Antiretroviral Therapysuppressed Subjects by Engineered Immune-mobilizing T-cell Receptors. Mol Ther 24, 1913-1925, doi:10.1038/mt.2016.114 (2016).

198 Jo, J. et al. Toll-like receptor 8 agonist and bacteria trigger potent activation of innate immune cells in human liver. PLoS Pathog 10, e1004210, doi:10.1371/journal.ppat.1004210 (2014).

199 Caskey, M., Klein, F. \& Nussenzweig, M. C. Broadly neutralizing anti-HIV-1 monoclonal antibodies in the clinic. Nat Med 25, 547-553, doi:10.1038/s41591-0190412-8 (2019). 
200 Bar-On, Y. et al. Safety and antiviral activity of combination HIV-1 broadly neutralizing antibodies in viremic individuals. Nat Med 24, 1701-1707, doi:10.1038/s41591-018-0186-4 (2018).

201 Mendoza, P. et al. Combination therapy with anti-HIV-1 antibodies maintains viral suppression. Nature 561, 479-484, doi:10.1038/s41586-018-0531-2 (2018).

202 Eren, R. et al. Preclinical evaluation of two human anti-hepatitis B virus (HBV) monoclonal antibodies in the HBV-trimera mouse model and in HBV chronic carrier chimpanzees. Hepatology 32, 588-596, doi:10.1053/jhep.2000.9632 (2000).

203 Galun, E. et al. Clinical evaluation (phase I) of a combination of two human monoclonal antibodies to HBV: safety and antiviral properties. Hepatology 35, 673679, doi:10.1053/jhep.2002.31867 (2002).

204 Golsaz-Shirazi, F. et al. Construction of a hepatitis B virus neutralizing chimeric monoclonal antibody recognizing escape mutants of the viral surface antigen (HBsAg). Antiviral Res 144, 153-163, doi:10.1016/j.antiviral.2017.06.013 (2017).

205 Kucinskaite-Kodze, I. et al. New broadly reactive neutralizing antibodies against hepatitis B virus surface antigen. Virus Res 211, 209-221, doi:10.1016/j.virusres.2015.10.024 (2016).

206 Zhang, T. Y. et al. Prolonged suppression of HBV in mice by a novel antibody that targets a unique epitope on hepatitis B surface antigen. Gut 65, 658-671, doi:10.1136/gutjnl-2014-308964 (2016).

$207 \mathrm{Li}, \mathrm{D}$. et al. A potent human neutralizing antibody Fc-dependently reduces established HBV infections. Elife 6, doi:10.7554/eLife.26738 (2017).

208 Oliviero, B. et al. Hepatitis C virus-induced NK cell activation causes metzincinmediated CD16 cleavage and impaired antibody-dependent cytotoxicity. J Hepatol 66, 1130-1137, doi:10.1016/j.jhep.2017.01.032 (2017).

209 Kruse, R. L. et al. In Situ Liver Expression of HBsAg/CD3-Bispecific Antibodies for HBV Immunotherapy. Mol Ther Methods Clin Dev 7, 32-41, doi:10.1016/j.omtm.2017.08.006 (2017). 
Key points

- Unprecedented opportunities exist to develop immunotherapeutic approaches that complement novel antivirals to achieve sustained control of residual HBV in chronic HBV infection (CHB).

- Adaptive immune responses (HBV-specific T cells and B cells) provide precise antiviral targeting of HBV-infected hepatocytes and/or virions, but also have the potential to trigger tissue damage.

- HBV-specific T cell and B cell responses should be examined in parallel to consider their cross-talk, complementary effector mechanisms and their features of dysfunction in CHB.

- Inadequate HBV-specific T cell and B cell responses might be restored by immunogenic therapeutic vaccines, and released from inhibition by antigen load reduction or more specific immunomodulation such as checkpoint inhibition.

- Alternatively, the failed endogenous adaptive response can be replaced with targeted exogenous T cell or B cell-derived HBV-specific effectors. 
Box 1 | Key defects in HBV-specific T cell and B cell immunity in CHB

\section{CD8 $^{+} \mathrm{T}$ cells}

- Numerical depletion of HBV-specific T cells

- BIM-mediated apoptosis

o NK cell-mediated deletion

- Inhibition by PD1 and other checkpoints

- Impaired effector function:

○ Cytokines (for example, IFN $\gamma$, TNF)

- Cytotoxic mediators (for example, perforin, granzyme)

- Reduced proliferative expansion

- Impaired metabolism

- Arginine deprivation

○ Mitochondrial defects

- Inadequate CD4 help

\section{B cells}

- HBsAg-specific B cells numerically maintained

- Inhibition by PD1; additional checkpoints are unknown

- Impaired effector function:

○ Cytokines (for example, IL-6, TNF)

O anti-HBs antibody

- Impaired differentiation to plasma cells

- Unknown metabolism

- Inadequate $T_{F H}$ cell help

anti-HBs, HBsAg-specific antibodies; HBsAg, HBV surface antigen; $\mathrm{CHB}$, chronic HBV infection; NK, natural killer; $\mathrm{T}_{\mathrm{FH}}, \mathrm{T}$ follicular helper cell 
Box 2 | Therapeutic approaches to adaptive immune control of $\mathrm{CHB}$

\section{Restoration}

- Therapeutic vaccination*

- PD1 blockade*

- Alternative T cell and B cell checkpoint blockade

- TLR agonists*

- Metabolic or mitochondrial targets

- Blockade of regulatory interactions (for example, NK cells)

- Reduction of antigen load*

\section{Replacement}

- TCR redirected T cells*

- CAR T cells

- Solube TCRs (for example, ImmTAVs)

- Monoclonal antibodies*

- Bispecific antibodies

CAR, chimeric antigen receptor; $\mathrm{CHB}$, chronic HBV infection; ImmTAVs, immune-mobilising monoclonal TCRs against viruses; NK, natural killer; TCR, T cell receptor; TLR, Toll-like receptor

* already tested in patients with HBV or HBV-related hepatocellular carcinoma 
Figure 1 | Antiviral functions of HBV-specific CD8 ${ }^{+}$T cells. Schematic depiction of key effector functions of $\mathrm{HBV}$-specific $\mathrm{CD}^{+} \mathrm{T}$ cells upon peptide recognition a | Non-cytolytic control of HBV through the production of antiviral cytokines (for example, IFN $\gamma$ or TNF) and induction of APOBEC3 (via lymphotoxin $\beta$ receptor (LT $\beta R$ ) engagement on infected hepatocytes or production of IFN $\gamma$ ) decreases viral intermediates and covalently closed circular DNA (cccDNA) but not integrated HBV DNA. b | Elimination of HBV-infected hepatocytes through cytotoxic mechanisms such as perforin or granzyme B removes all viral forms including integrated DNA.

Figure 2 | Antiviral functions of B cells and antibodies in HBV infection. Putative mechanisms by which $B$ cells and plasma cells can contribute to immune control in HBV infection are shown. These include the production of HBV surface antigen (HBsAg)-specific antibodies (anti-HBs) that: are sequestered by circulating HBsAg (subviral particles) (1); bind $\mathrm{HBsAg}$ on virions to block virus attachment via heparan sulfate proteoglycans (HSPGs) or entry via sodium taurocholate co-transporting polypeptide (NTCP) (2); bind HBsAg on the surface of HBV-infected hepatocytes to induce Fc-dependent elimination via antibodydependent cell-mediated cytotoxicity (ADCC) by natural killer (NK) cells (3); bind HBsAg on the surface of virions to induce antibody-dependent cellular phagocytosis (ADCP) by Kupffer cells (4); or form HBsAg-anti-HBs immune complexes binding dendritic cells to induce vaccinal effects (5). Another mechanism involves production of antiviral cytokines (for example, IL-6) by HBV-specific B cells that inhibit HBV transcription and covalantly closed circular DNA (cccDNA) acetylation, and downregulate NTCP expression (6). BCR, B cell receptor.

Figure 3 | Interactions between B cells and $\mathrm{CD4}^{+} \mathrm{T}$ cells. Schematic representation of key pathways required for reciprocal $B$ cell and $C D 4^{+} T$ cell activity that: activate cognate $T$ follicular helper $\left(T_{F H}\right)$ cells through $B$ cell receptor $(B C R)$-mediated antigen endocytosis and subsequent processing and presentation on major histocompatibility complex (MHC) class II (dotted line); promote B cell survival (via IL-4) and proliferation (via CD40-CD40-L engagement); regulate $\mathrm{CD}^{+}{ }^{+} \mathrm{T}$ cell differentiation to $\mathrm{T}_{\mathrm{FH}}$ cells (via IL-6, IL-21 or inducible T cell co-stimulator (ICOS)-ICOS ligand (ICOS-L) engagement) and B cell differentiation to plasma cells (via IL-4 or IL-21); and promote antibody mutation and class-switching (via IL-4 or IL-21) $)^{88}$. Both $\mathrm{T}_{\mathrm{FH}}$ and $\mathrm{B}$ cell differentiation and effector function can be controlled by $\mathrm{FOXP3}^{+}$regulatory $\mathrm{CD}^{+} \mathrm{T}\left(\mathrm{T}_{\text {reg }}\right.$ ) cells and/or $\mathrm{T}$ follicular regulatory $\left(\mathrm{T}_{\mathrm{FR}}\right)$ cells. IL-4R, IL-4 receptor; IL-6R, IL-6 receptor; IL-21R, IL-21 receptor; TCR, T cell receptor. 
Figure 4 | Modulation of adaptive immunity by immunotherapeutic approaches. Schematic representation of key immunotherapeutic approaches theorised to harness (upper box) or supplement (lower box) adaptive immunity in chronic HBV infection. Endogenous adaptive immunity is harnessed with therapeutic vaccination to boost existing or induce de novo HBV-specific T cell and B cell responses. These responses are accompanied by complementary immunomodulatory approaches, either direct (for example, checkpoint modulation, metabolic rescue via mitochondrial antioxidants or blockade of suppressive cells) or indirect (for example antigen load reduction). Replacing endogenous adaptive immunity can be acheived with exogenous adaptive mediators, either T cell-based (T cell receptor (TCR)-redirect, chimeric antigen receptor (CAR) T cells or soluble TCRs (for example, immune-mobilising monoclonal TCRs against viruses (ImmTAVs)) or antibody-based (monoclonal or bispecific). CTLA4, cytotoxic T-lymphocyte-associated protein 4; MDSC, myeloid-derived suppressor cell; NK, natural killer; PD1, programmed cell death protein 1; siRNA, small interfering RNA.

\section{Acknowledgements}

M.K.M. is supported by funding from the Wellcome Trust, Cancer Research UK, Medical Research Foundation and the National Institute for Health Research. A.R.B. was funded by a F. Hoffmann-La Roche-University College London joint Impact Studentship.

\section{Competing interests}

M.K.M. receives collaborative research funding from Gilead Sciences and Immunocore and has served as a consultant or on advisory boards for Arbutus Biopharma, F. Hoffmann-La Roche, Gilead Sciences, Immunocore and Janssen.

\section{Publisher's note}

Springer Nature remains neutral with regard to jurisdictional claims in published maps and institutional affiliations.

\section{Reviewer information}

Nature Reviews Gastroenterology \& Hepatology thanks U. Protzer and the other anonymous reviewer for their contribution to the peer review of this work.

\section{ToC Blurb}

Multiple therapeutic approaches are being developed to achieve sustained, off-treatment suppression of HBV. In this Review, the authors examine T cell and B cell responses to HBV and the potential for immunotherapies to restore or release endogenous adaptive immunity by direct or indirect approaches. 
Figure 1: Antiviral functions of $\mathrm{HBV}$-specific $\mathrm{CD} 8^{+} \mathrm{T}$ cells

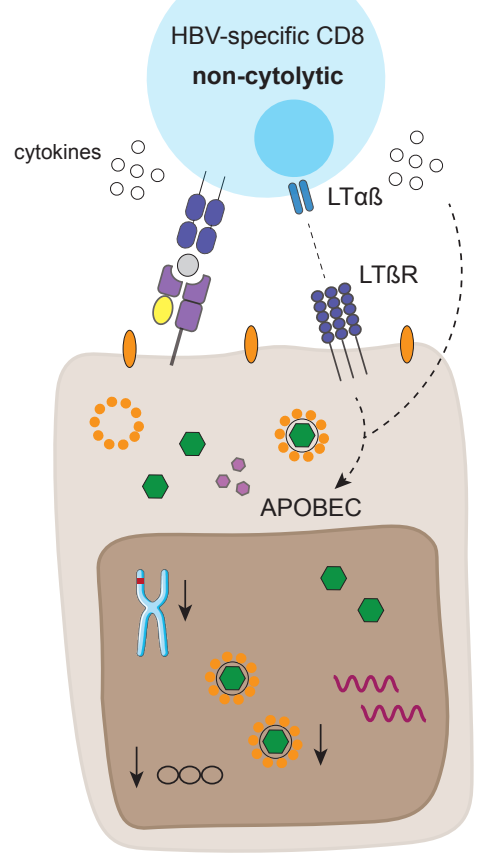

a. non-cytolytic antiviral activity

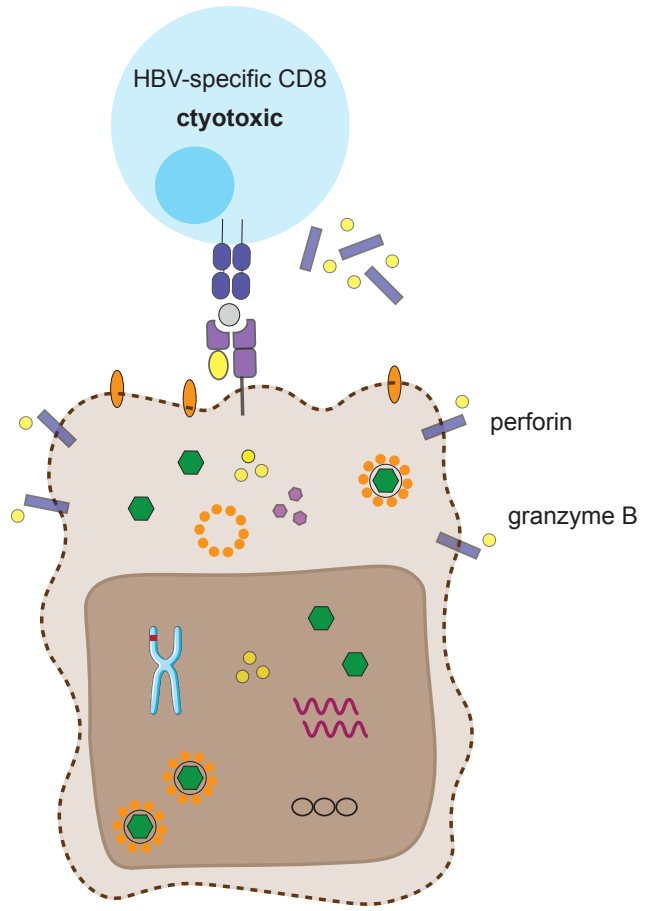

b. elimination of infected hepatocytes

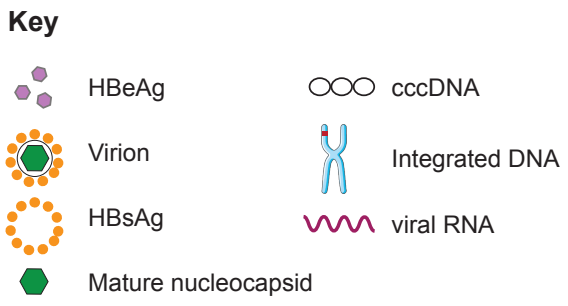


Figure 2: Antiviral functions of B cells and antibodies in HBV infection

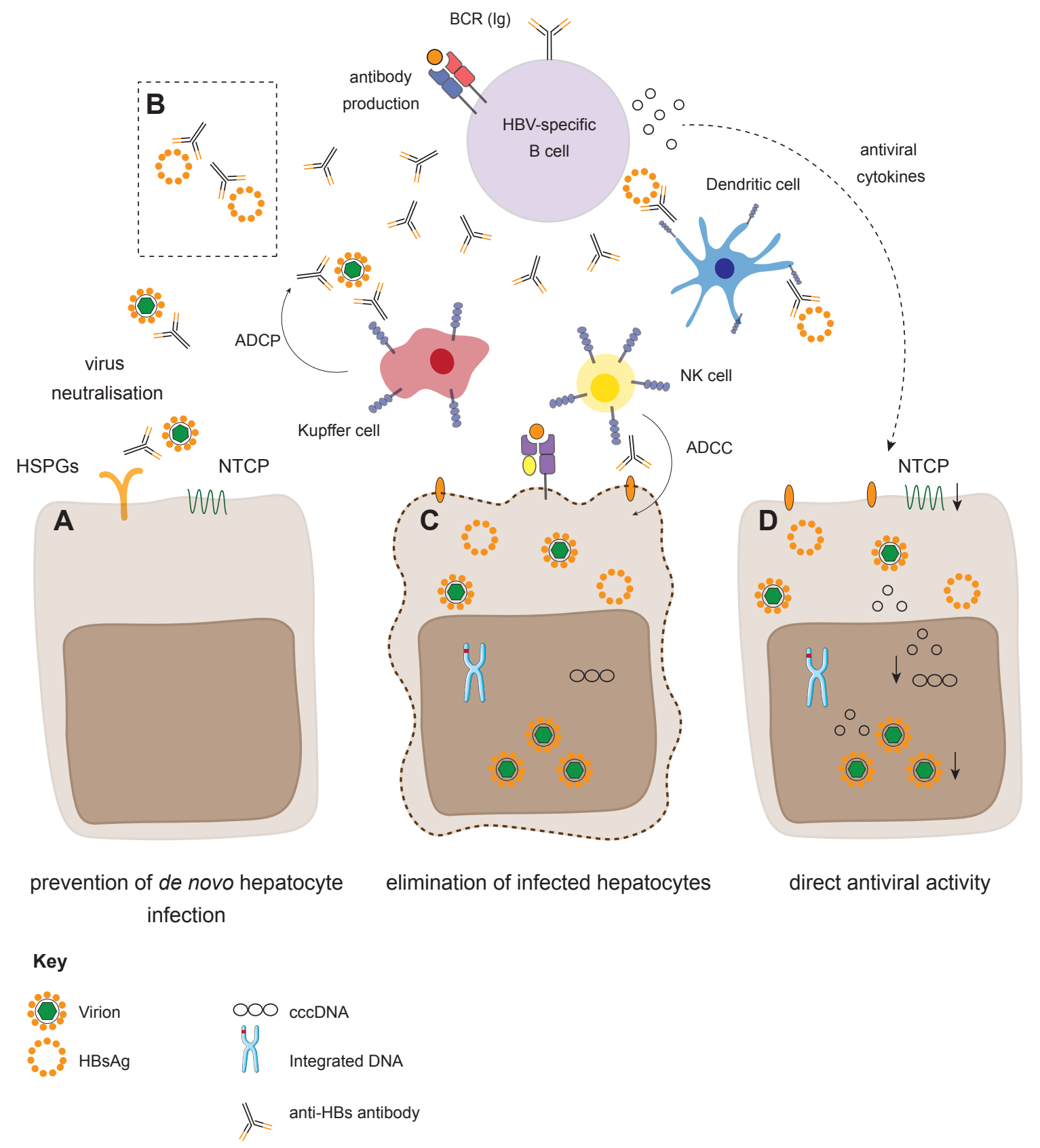


Figure 3: $\mathrm{B}$ and $\mathrm{CD} 4 \mathrm{~T}$ cell interactions

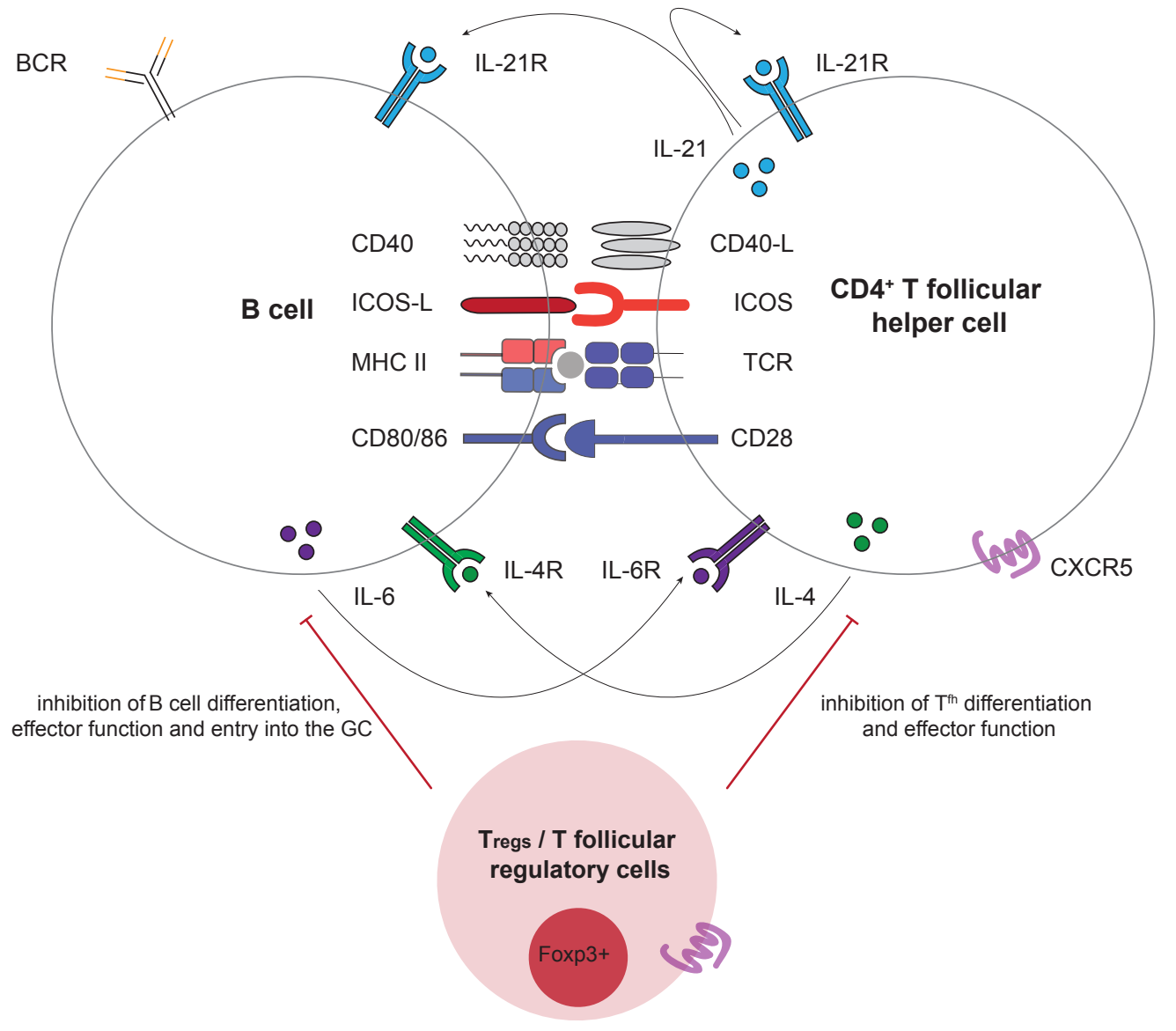


Figure 4: Modulation of adaptive immunity by immunotherapeutic approaches

Direct immunotherapeutic approaches to restore endogenous adaptive immunity

therapeutic vaccination

checkpoint modulation eg. PD-1, CTLA-4

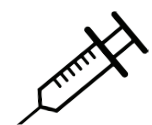

reduction of antigen load
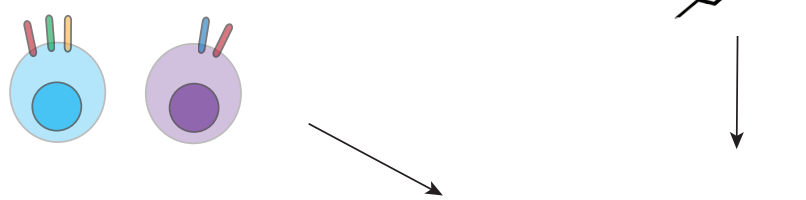

eg. by siRNA

boosting existing or de-novo HBV-specific

$T$ and $B$ cell responses

metabolic

rescue
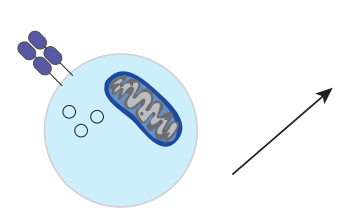

immunoregulatory cytokines

eg. IL-12, IFNa

$$
0_{0}^{0} 0_{0}^{0}
$$

$\mathrm{CD}^{+} \mathrm{T}$ cells

HBV-specific

$B$ cells
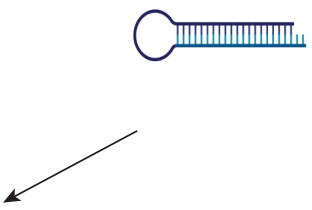

alleviation of NK cell or MDSC

suppression of antiviral T cells
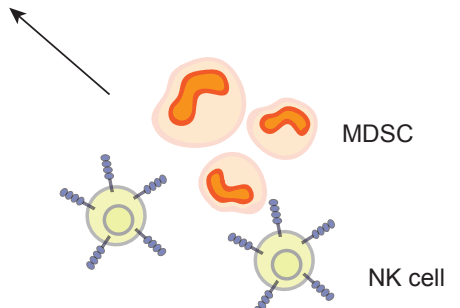

TCR-redirected and CAR T cells
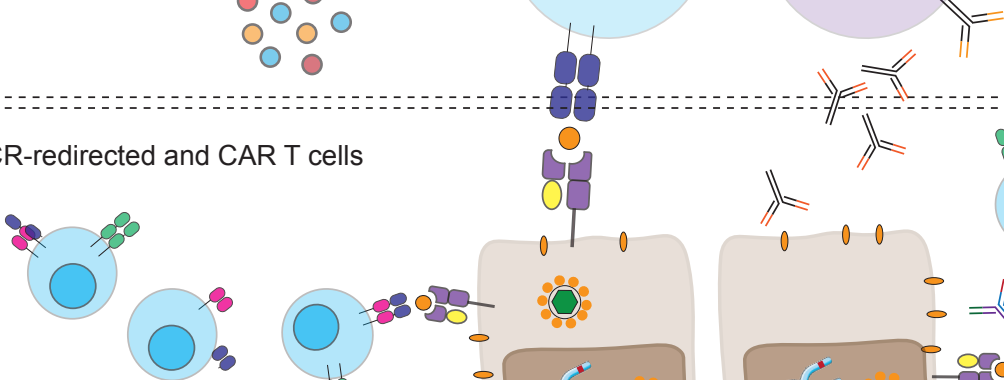

Non-specific T cell<smiles>C1=C2CC=C2CC1</smiles>
$\lambda$

80<smiles>[CH]1CC1</smiles>
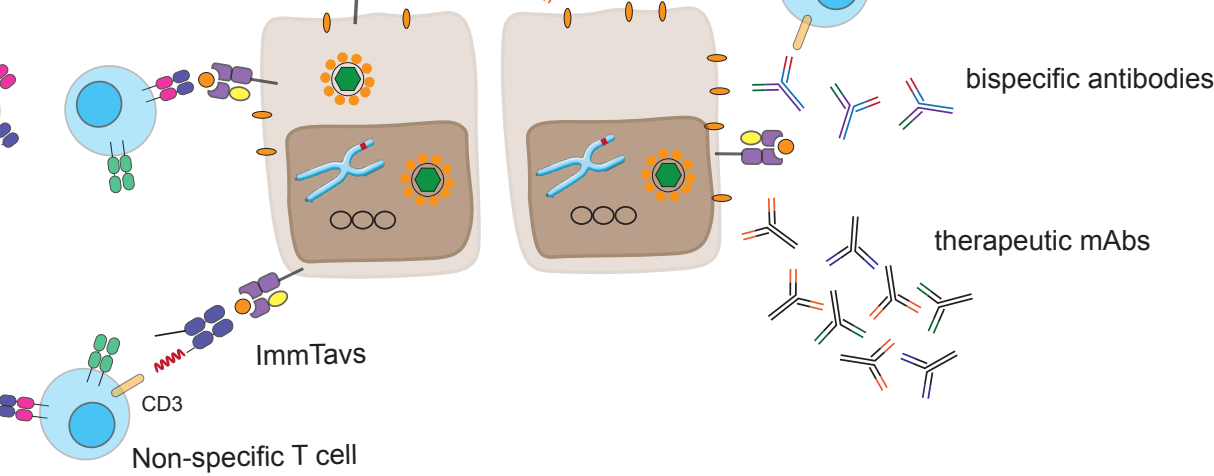

○०

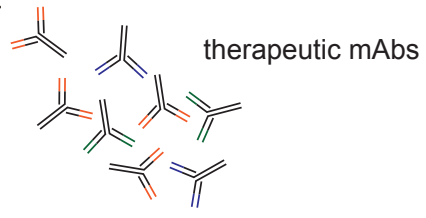

Immunotherapeutic approaches to replace endogenous adaptive immunity 